\title{
O desenvolvimento da Ortodontia no Brasil e no mundo
}

\author{
Oswaldo de Vasconcellos Vilella*
}

\begin{abstract}
Resumo
Ensino, organização e literatura. São esses os principais pilares que sustentam toda e qualquer especialidade. No presente artigo procurou-se avaliar de que maneira a Ortodontia brasileira foi dimensionada dentro do ensino oficial, se organizou em torno de suas associações de classe e qual literatura especializada estava à disposição de seus precursores. Precursores como Antônio Gonçalves Pereira da Silva, provavelmente o primeiro professor a ensinar a confecção de aparelhos ortodônticos; Carlos de Almeida Lustosa, o primeiro brasileiro a se tornar especialista em Ortodontia;. Carlos Alves da Costa, autor do primeiro livro-texto em Português totalmente dedicado à especialidade. Por outro lado, para que se pudesse perceber de que maneira essas mudanças foram acontecendo ao longo do tempo e correlacioná-las com as modificações em nível mundial, um resumo histórico da Ortodontia em seu universo geral foi organizado. De acordo com o que foi pesquisado, pode-se afirmar que foram necessários aproximadamente 50 anos para a consolidação dos centros de pós-graduação no Brasil. Também é verdade que o esforço das instituições de ensino e entidades de classe contribuiu para criar as bases do desenvolvimento científico da Ortodontia brasileira. No presente momento, entretanto, parece sensato supor que o próximo passo deverá ser o estabelecimento de normas que regulamentem a pós-graduação, de modo a aprimorar a formação profissional dos novos especialistas.
\end{abstract}

Palavras-chave: Ortodontia brasileira - história. Ortodontia brasileira - ensino. Ortodontia brasileira - precursores. Ortodontia brasileira - literatura. Ortodontia brasileira - associações de classe.

\section{INTRODUÇÃO}

A Ortodontia é a mais antiga das especialidades da Odontologia, tendo sido a primeira a se organizar de fato e de direito. Essa informação foi registrada em relatos de historiadores da Odontologia, sendo que, atualmente, informações sobre nossa profissão são procuradas em todas as partes do mundo. Cada vez mais se conhecem suas origens, seus precursores e pioneiros, sendo este conhecimento fundamental para o total entendimento do atual estágio evolutivo em que se encontra a Odontologia ${ }^{14}$.

Entretanto, ainda existem poucos registros sobre as origens e o desenvolvimento da Ortodontia brasileira em nossas escolas e associações. Isso não ocorre, por exemplo, nos Estados Unidos, pois Edward Hartley Angle, um dos fundadores e primeiro presidente da Sociedade Americana de Or-

* Professor Doutor da Disciplina de Ortodontia da FO-UFF/RJ. Coordenador do curso de especialização em Ortodontia da FO-UFF/RJ. 
todontistas, em 1901, procurou estabelecer uma comissão de historiadores e literatos, dentro do grupo diretor, afirmando ser essa a melhor maneira para se fazer entender a importância da especialidade e seus propósitos ${ }^{40}$. A sábia orientação foi, de certa forma, seguida e muitos trabalhos históricos foram elaborados.

Por meio desses relatos, hoje se pode compreender melhor a evolução da especialidade e conhecer o trabalho de muitos dentistas e ortodontistas que, no passado, utilizavam apenas procedimentos mecânicos, mas que puderam estabelecer uma ciência meticulosa e bem fundamentada, objetivando a correção das más formações dentárias e faciais, com base no princípio científico da oclusão dentária norma ${ }^{14}$.

Por conseguinte, tornou-se relevante responder à seguinte indagação: afinal, teria o Brasil uma história ortodôntica merecedora de ser publicada? Para responder foi necessário recuperar nossa memória profissional, pelo menos em parte. Foram desenvolvidas pesquisas de âmbito documental e doutrinário. Recursos fotográficos também foram utilizados, para melhor elucidar fatos históricos. Visando facilitar a compreensão de algumas etapas do desenvolvimento da Ortodontia brasileira, o texto foi organizado por assuntos, a saber: 1) a Ortodontia no mundo; 2) o ensino da Ortodontia no Brasil; 3) os precursores no Brasil; 4) a literatura ortodôntica brasileira; 5) a indústria ortodôntica nacional; 6) as associações de classe.

\section{A ORTODONTIA NO MUNDO}

Desde a antiguidade, dentes apinhados e irregulares têm sido um problema para alguns indivíduos e tentativas para corrigir essas desordens datam de, pelo menos, 1.000 anos a.C. Aparelhos ortodônticos primitivos foram encontrados em escavações gregas e etruscas. Naquela época, já havia consciência da má aparência causada pelos dentes torcidos, conforme relataram Hipócrates (460-377 a.C.) e Aristóteles (384-322 a.C.). Celso, um escritor romano, chegou a afirmar, em
25 a.C., que os dentes podiam ser movimentados pela pressão digital: "Caso um segundo dente esteja irrompendo numa criança antes que o primeiro tenha esfoliado, o que deve ser feito é extrair e empurrar diariamente o novo dente com o dedo até que ele alcance sua posição correta" ${ }^{\prime \prime}$.

Durante a idade média não houve progresso. A Odontologia entrou num período de acentuado declínio, assim como todas as demais ciências. No início do século XVIII, a França era o país mais adiantado no campo da Odontologia, o que se deveu, em grande parte, aos esforços de um homem: Pierre Fauchard (1678-1761) ${ }^{49}$ (Fig. 1). Tendo iniciado sua carreira como cirurgião militar, devotou-se, em seguida, integralmente à Odontologia, sendo considerado por muitos o "pai da Odontologia moderna". Em 1728, ele publicou a obra intitulada Le chirurgien dentiste ou Traitè des dents, em dois volumes, separando efetivamente a Odontologia dos demais ramos da Cirurgia ${ }^{38}$. Neste trabalho, Fauchard apresentou um aparelho

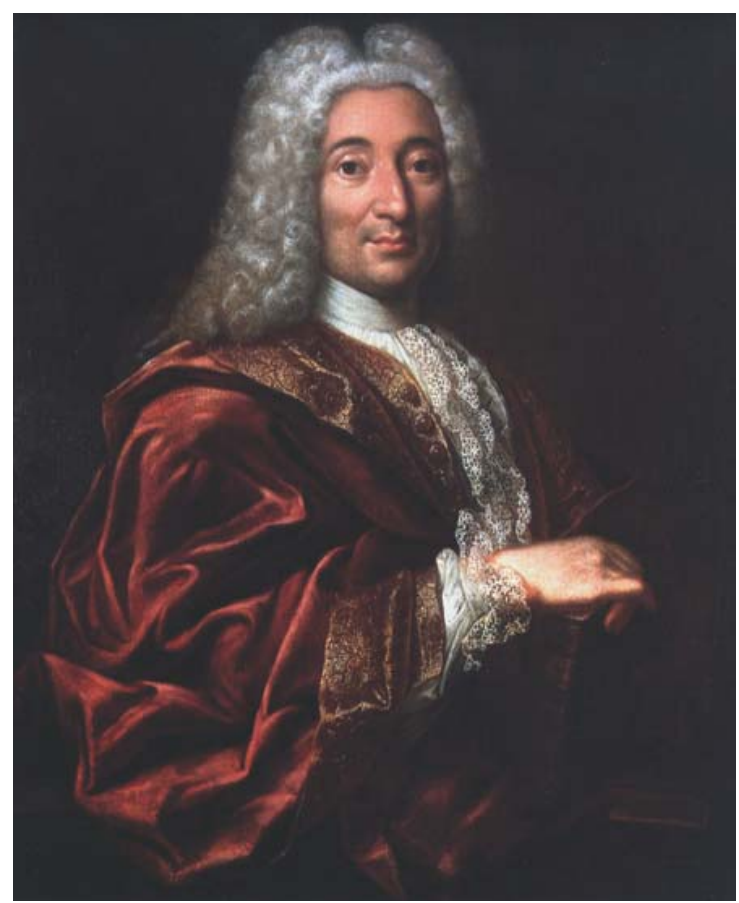

FIGURA 1 - Pierre Fauchard. Retrato pintado provavelmente entre 1723 e 1728 , quando Fauchard tinha entre 45 e 50 anos de idade. 


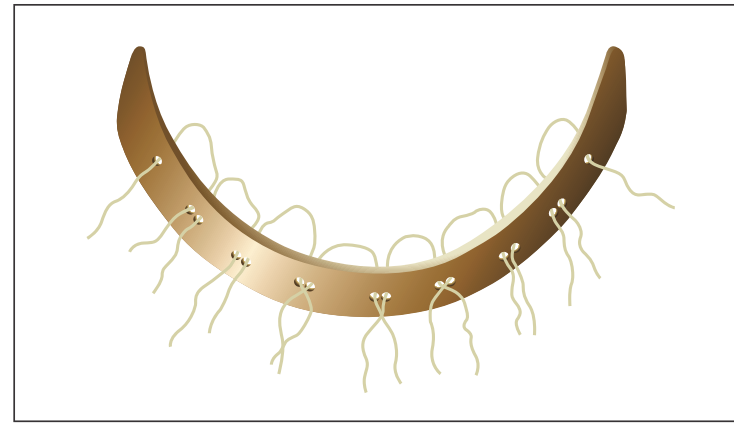

FIGURA 2 - Aparelho bandeau, idealizado por Fauchard, constituído por uma cinta de metal, perfurada para receber ligaduras de fibra, com as quais eram amarrados os dentes.

denominado bandeau (Fig. 2), que consistia de uma tira de metal flexionada em forma de arco e perfurada em locais adequados. Os dentes mal posicionados eram movimentados através da ação de fios de fibra, que passavam ao redor de suas coroas e através das perfurações. Quando se amarrava o fio sob pressão, aplicava-se a força sobre os dentes, conseguindo-se apenas o movimento de inclinação. Foi o primeiro arco expansor introduzido na Ortodontia, mas na prática, como não apresentava estabilidade, não havia maneira de mantê-lo corretamente em posição no arco dentário ${ }^{46}$. Naquela época, a principal finalidade do tratamento era o alinhamento dos dentes anteriores, principalmente os da maxila. Os métodos empregados por Fauchard incluíam luxação e "reposicionamento" de dentes em má posição ${ }^{49}$. Esses princípios pouco evoluíram até meados do século seguinte.

No início do século XIX, os praticantes da Odontologia, na Europa e nos Estados Unidos, pertenciam basicamente a três categorias distintas: 1) pessoas treinadas como joalheiros, ferreiros e outros, com grande habilidade manual e que praticavam a Odontologia ao lado de outras atividades. Eram, quase sempre, não alfabetizados e sem qualificação; 2) praticantes de Medicina, sem nenhuma formação em Odontologia, e que se apresentavam como dentistas, aprendendo à medida que trabalhavam e 3) homens qualificados através de estágios junto a profissionais de grande reputação.

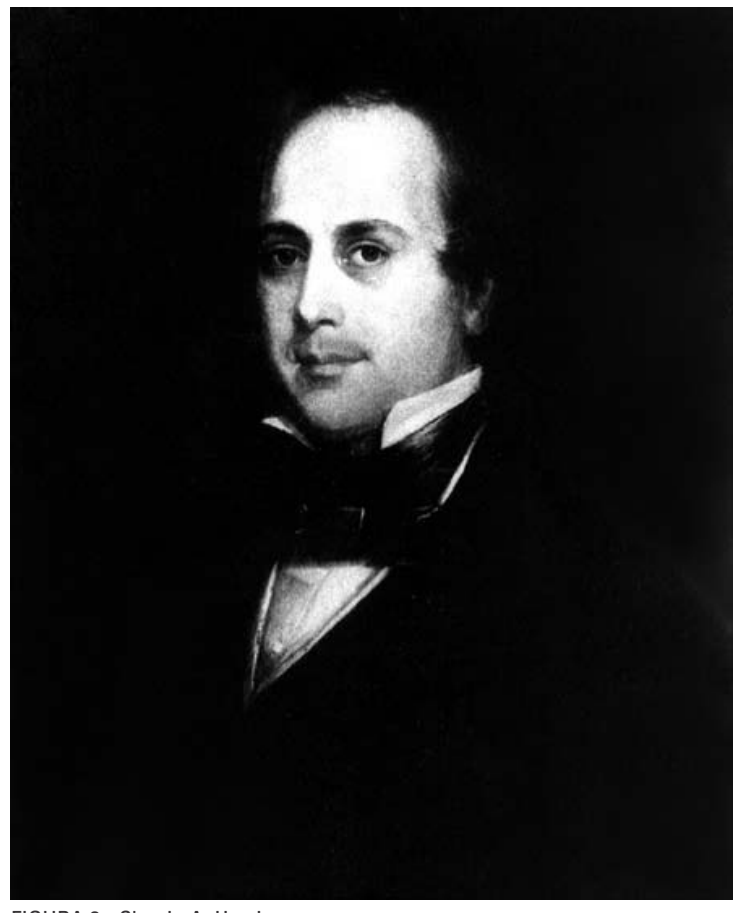

FIGURA 3 - Chapin A. Harris.

Esse era o menor grupo, embora, provavelmente, o mais influente ${ }^{28}$.

Neste último caso, se encaixava Horace H. Hayden (1769-1844), que praticava a Odontologia em Baltimore. Ele rapidamente alcançou grande reputação, tendo contribuído com artigos em diversos periódicos especializados em Medicina. Em 1810 ele conseguiu a primeira licença emitida nos Estados Unidos para praticar a Odontologia, concedida pela Faculdade de Medicina de Maryland, tornando-se, ainda, um dos membros da instituição. Nove anos mais tarde, foi convidado para lecionar Odontologia para os alunos do curso de Medicina, o que acabou acontecendo de 1823 a 1825 . Entretanto, como os estudantes demonstraram pouco interesse no assunto, o curso foi suspenso. No início da década de 1830, ele aceitou ser o preceptor do jovem Chapin A. Harris (1806-1860) (Fig. 3), que praticava, simultaneamente, a Medicina e a Odontologia. Harris fixou-se definitivamente em Baltimore a partir de $1835^{38}$. 
Pode-se afirmar que a Odontologia contemporânea tem como alicerces a educação, a organização e a literatura; sendo assim a Odontologia norte-americana, particularmente, sofreu um enorme avanço com as contribuições desta dupla de pioneiros. Devido ao fracasso da primeira tentativa (1823-1825) em ministrar aulas de Odontologia na Faculdade de Medicina, Hayden e Harris idealizaram a formação de um instituto isolado. No dia 6 de março de 1840 foi fundado o Baltimore College of Dental Surgery (Maryland), que se tornou a primeira Escola de Odontologia no mundo. O corpo docente era constituído por quatro professores, sendo que dois eram médicos e os outros dois dentistas: Hayden e Harris. Naquele mesmo ano, Horace Hayden fundou, com o auxílio de Harris, a American Society of Dental Surgeons, a primeira associação odontológica em nível nacional. Em 1839, foi editado o primeiro periódico especializado, The American Journal of Dental Science, por Harris e alguns outros den$\operatorname{tistas}^{38}$.

Até meados de 1840, a Odontologia não possuía nomenclatura própria e dependia completamente de termos médicos e antropológicos. Em 1845, entretanto, William Rogers publicou o primeiro dicionário de termos dentários, sanando, em parte, as dificuldades de comunicação encontradas pelos dentistas. Quatro anos antes, o vocábulo orthodontosie havia sido cunhado pelo francês Joachim Lefoulon para designar o tratamento das deformidades congênitas e acidentais da boca. Em 1849, o termo foi modificado para orthodontia $($ do Grego: orto $=$ reto; e dons $=$ dente $)$, por Chapin Harris $^{28}$.

Harris ofereceu à Odontologia, entre outras coisas, um vasto legado literário. Talvez sua maior contribuição à literatura odontológica tenha sido o livro The dental art: a practical treatise on dental surgery, publicado pela primeira vez em 1839 e reeditado por 74 anos, alcançando a incrível marca de 30 edições. Nesta obra, Harris já preconizava conceitos básicos da Ortodontia atual, tais como a extração de dentes permanentes para a correção dos apinhamentos dentários severos, como também a necessidade de remoção da causa das irregularidades, a fim de que a estabilidade do tratamento pudesse ser alcançada ${ }^{28}$.

À medida que a Odontologia se desenvolvia nos séculos XVIII e XIX, um grande número de dispositivos para a regularização dos dentes foi descrito por vários autores e utilizado esporadicamente por dentistas da época. Em meados do século XIX, a Odontologia européia já podia ser considerada atrasada em relação à Odontologia norte-americana ${ }^{38}$. A partir da segunda metade do século XIX foram introduzidas várias inovações que seriam muito úteis aos ortodontistas.

O francês J. M. Alexis Schangé (1807-?) inventou a banda ortodôntica ajustável com parafuso, que passou a ser utilizada em substituição às coroas metálicas. Em 1861, C. R. Coffin preconizou o uso do fio flexível, feito de cordas de piano, na Ortodontia. Ainda que houvesse sido concebido para ser utilizado em aparelhos removíveis, o fio com memória elástica viria a ser, literalmente, a mola propulsora que permitiria o pleno desenvolvimento da Ortodontia fixa. Em 1871, com o advento do cimento odontológico, introduzido por William E. Magill, a prática ortodôntica seria radicalmente modificada, apesar de muitos ortodontistas não terem associado a descoberta com o tratamento. Entretanto, sem o cimento, a ortodontia fixa, conforme é realizada atualmente, não teria sido possível ${ }^{49}$. Em 1879, Norman W. Kingsley (1825-1896) desenvolveu a tração occipital, introduzindo definitivamente a força extrabucal aplicada sobre o arco superior. Embora E. G. Tucker tenha descrito o uso de borrachas elásticas em 1846, a nova invenção não se tornou importante até que Henry A. Baker a utilizou para obter força intermaxilar e corrigir protrusões. A partir de então, este método passou a ser conhecido como Baker anchorage $e^{50}$.

Nessa época, surgiu um nome que influenciaria profundamente o desenvolvimento da Ortodontia 


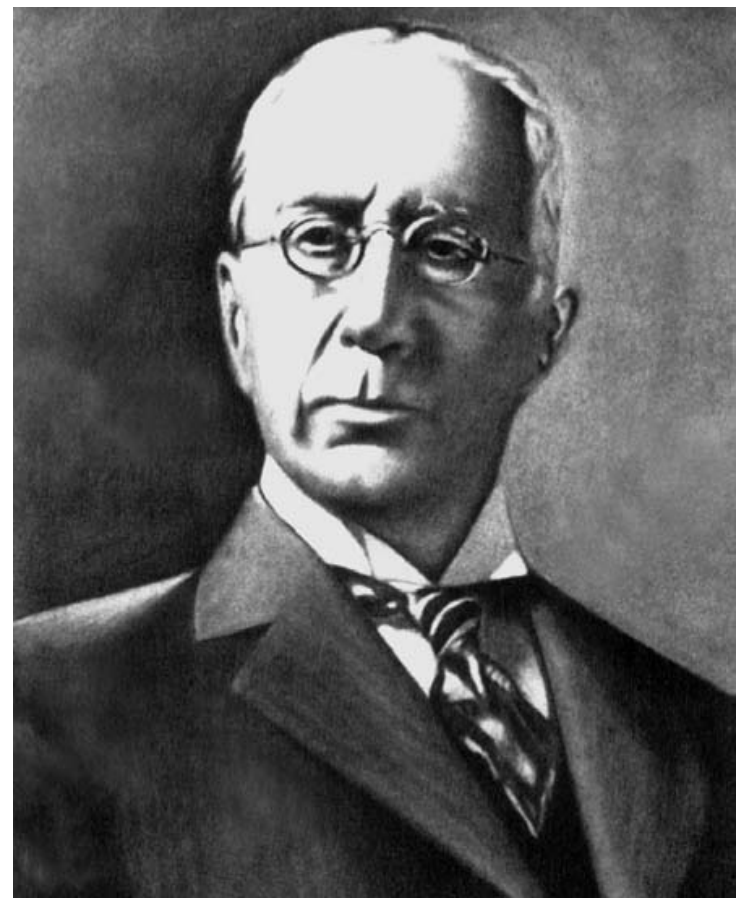

FIGURA 4 - Edward Hartley Angle.

nos Estados Unidos e no mundo. Edward Hartley Angle (1855-1930) (Fig. 4) nasceu na cidade de Herrick, no estado da Pennsylvania. Pouco antes de graduar-se em Odontologia, no final de 1878, ele começou a se interessar em regularizar a posição dos dentes. Após ter chefiado departamentos em várias escolas dentárias, ele estava frustrado por não conseguir separar a Ortodontia das outras disciplinas do currículo, até que finalmente estabeleceu o primeiro departamento de Ortodontia dentro de uma universidade (Marion Sims Dental College), em 1897, na cidade de Saint Louis (Missouri/EUA), para onde havia se mudado em 1895. Mais tarde, chegaria à conclusão de que seria mais efetivo lecionar para pequenos e seletos grupos de alunos em sua clínica privada ${ }^{50}$. Assim, em 1900 ele iniciou sua própria escola de Ortodontia, a $A n$ gle School of Orthodontia. Entre seus primeiros alunos estavam Strang, Dewey, Pullen, Mershon, McCoy, Oppenheim, Weinberger e Noyes. Posteriormente, transferiria a escola para as cidades de New York (New York - 1907) e New London (Connecticut - 1908). Angle parou de clinicar em 1911 para se dedicar integralmente ao ensino. Em 1916 ele fez sua última grande mudança, para Pasadena (Califórnia). Ali as primeiras turmas foram restritas a apenas 3 alunos, entre os quais estiveram Atkinson, Broadbent, Brodie, Begg, Linn, Stallard, Steiner, Taylor e Wilkinson ${ }^{37}$. Angle insistia que eles fossem versados em matérias básicas, como Anatomia, Histologia, Embriologia e Rinologia, além de Fotografia e Artes ${ }^{50}$.

Em 1887 ele apresentou um artigo intitulado Irregularities of the teeth durante o IX Congresso Médico Internacional. Este artigo foi considerado a primeira edição do seu livro-texto, o qual teve sete edições, cada qual apresentando um título diferente, sendo a última publicada em 1907 (Treatment of malocclusion of the teeth ${ }^{23}$. Antes de 1887 era necessário desenhar e fabricar um aparelho para cada paciente. Porém, no final do século XIX os ortodontistas já podiam contar com fio, bandas, cimento e solda. Angle, então, projetou uma aparelhagem padrão, composta por uma coleção de peças pré-fabricadas (Angle System), que podiam ser montadas em várias combinações ${ }^{50}$.

Em poucos anos ele padronizou sua aparelhagem num sistema composto por um arco pesado soldado à face vestibular das bandas dos primeiros molares, capaz de executar a expansão do arco dentário até conseguir um alinhamento satisfatório. Desenvolveu várias versões deste aparelho, que denominou arco E ( $E$ arch appliance). Como os arcos dentários eram expandidos em todas as direções, os aparelhos de contenção tinham que ser usados pelo paciente durante muito tempo, pois, quando removidos, diferentes graus de recidiva ocorriam ${ }^{46}$.

Sua classificação para as más oclusões, publicada em 1899, continua sendo a mais utilizada e amplamente aceita até os dias de hoje. Baseada na relação dos primeiros molares inferiores com a maxila, possibilitou que, pela primeira vez, as más oclusões fossem metodicamente caracteriza- 
das, sendo sua aceitação universal a maior prova de sua simplicidade e praticidade ${ }^{50}$.

Nos primeiros anos do século XX Angle iniciou um ataque vigoroso contra as extrações dentárias com finalidade ortodôntica. Os motivos que o levaram a tomar tal decisão ainda são discutidos. Certamente, a utilização dos elásticos intermaxilares contribuiu muito neste sentido. Através desse recurso, ele conseguia realizar a retração dos dentes superiores, ao mesmo tempo em que movimentava os dentes inferiores para frente, eliminando a discrepância ântero-posterior sem a necessidade de extrações, apesar de não ser possível conseguir a inclinação axial correta dos dentes ${ }^{46}$. Outra possibilidade teria sido a influência de Edmund Wuerpel, então presidente do Departamento de Artes da Universidade de Washington em Saint Louis. Wuerpel disse a Angle que não havia linha, conjunto de medidas ou fórmula que pudessem ser aplicados a toda face humana, e que havia diferenças individuais - devidas a características raciais, hereditariedade e muitos outros fatores - que não poderiam ser submetidas a um denominador comum. Após essa conversa, Angle passou a acreditar que cada dente deveria ocupar sua posição correta numa oclusão normal ${ }^{54}$. Portanto, não haveria porque extrair dentes. Esta posição acabaria gerando uma das maiores controvérsias da Ortodontia moderna. Calvin S. Case (1847-1923), outro grande inovador da Ortodontia e um dos primeiros a utilizar, junto com Henry Baker, elásticos com orientação de Classe II, advogava a necessidade de extrações para corrigir deformações faciais, atraindo a ira de Angle e seus discípulos. Seu artigo sobre extrações, publicado em 1911, provocou um dos mais amargos debates da Ortodontia, caracterizado por observações destemperadas e desprovidas de fundamento científico, onde a difamação pessoal era a ordem do dia ${ }^{50}$.

$\mathrm{Na}$ tentativa de obter o controle sobre a inclinação axial dos dentes, Angle iniciou uma série de novos experimentos, a partir de 1911. O aparelho de pino e tubo (pin and tube appliance) serviu admiravelmente para este propósito. Entretanto, sendo uma aparelhagem extremamente difícil de ser manipulada, apenas dois tratamentos foram finalizados. A cada movimento de um determinado dente, era preciso modificar a posição e, por vezes, também a inclinação do pino, e assim progressivamente, até que fosse alcançada a forma de arco ideal, o que determinava o comparecimento do paciente ao consultório em intervalos mínimos. Apesar de todas as dificuldades, este foi o primeiro aparelho a conseguir o movimento radicular ${ }^{1}$. Em 1915, ele desenvolveu o arco de cinta (ribbon arch appliance), muito mais fácil de ser construído e ativado. Braquetes foram introduzidos pela primeira vez nesse novo aparelho, sendo caracterizados por possuírem o slot numa posição vertical. $\mathrm{O}$ arco, que inicialmente era confeccionado acompanhando a má oclusão, era mantido em posição nos braquetes através de pinos de latão, ficando os dentes livres para se movimentarem. Contrariando as expectativas, o mecanismo não se mostrou efetivo nos casos onde era necessário o fechamento de espaços, e movimentos adequados só eram conseguidos em alguns grupos de dentes ${ }^{2}$. Com a experiência adquirida pelo uso dessa aparelhagem, ele começou a imaginar um novo mecanismo, capaz de contornar as adversidades. Modificou a forma dos braquetes e a posição dos slots, passando a colocá-los num plano horizontal, ao invés de vertical. $\mathrm{O}$ arco era mantido em posição, primeiro, através de ligaduras de latão e, posteriormente, por delicados fios de aço inoxidável. O braquete do arco de canto (Edgewise appliance) foi apresentado em 1928/29, e consistia de uma caixa retangular com uma fenda no meio (slot), cujas dimensões eram de $0,022 " x$ x 0,028 ". Esse desenho proporcionava maior precisão e um mecanismo de torque muito mais eficiente ${ }^{3,4,5,6}$.

Angle foi um homem de grande visão e força de vontade, extremamente perfeccionista e imaginativo, cujo pensamento se projetou através dos tempos, justificando plenamente o aparecimento de uma especialidade odontológica organizada e 
respeitada. Organizou a Ortodontia como a primeira especialidade no âmbito da Odontologia, o que ocorreu em junho de 1900, durante o encerramento da primeira sessão da Angle School of Orthodontia. Ele foi eleito o primeiro presidente da Society of Orthodontists, logo modificada para American Society of Orthodontists (ASO) e, em 1935, para American Association of Orthodontists $(\mathrm{AAO})^{51}$. O segundo artigo dos regulamentos dessa entidade caracterizava a ciência da Ortodontia como a primeira especialidade odontológica a se organizar. Deixou um legado de 40 invenções, 43 patentes e 60 trabalhos publicados, construído até $1930^{28}$.

Talvez seu aluno mais brilhante tenha sido Charles H. Tweed (Fig. 5), pós-graduado pela $A n-$ gle School of Orthodontia em 1928. Angle contava, então, 73 anos e, pela primeira vez, não estava à frente do curso, que foi ministrado de forma improvisada por George Hahn. Tweed estava com 33 anos. Angle ficou desapontado pelo modo como o aparelho Edgewise foi recebido e estava insatisfeito com as modificações que foram introduzidas por alguns de seus alunos. Decidiu escrever um artigo descrevendo a aparelhagem. Como Tweed havia recém terminado o curso, e Angle admirava sua habilidade, convidou-o para ajudá-lo. Durante 7 semanas eles trabalharam juntos e, nesse processo, tornaram-se grandes amigos. Angle fez dois importantes pedidos a seu jovem discípulo: 1) dedicar sua vida ao desenvolvimento do aparelho Edgewise e 2) empreender todo esforço possível para que a Ortodontia fosse reconhecida como especialidade da Odontologia. Tweed não desapontou o mestre. Assegurou a aprovação da lei que reconhecia a Ortodontia como primeira especialidade da Odontologia, nos Estados Unidos. Em 1929 o Estado do Arizona limitou a prática da Ortodontia aos especialistas e Tweed recebeu o primeiro certificado ${ }^{46}$.

Angle morreu no dia 11 de agosto de 1930, aos 75 anos de idade, e Tweed herdou sua firme convicção de que o ortodontista nunca deveria extrair

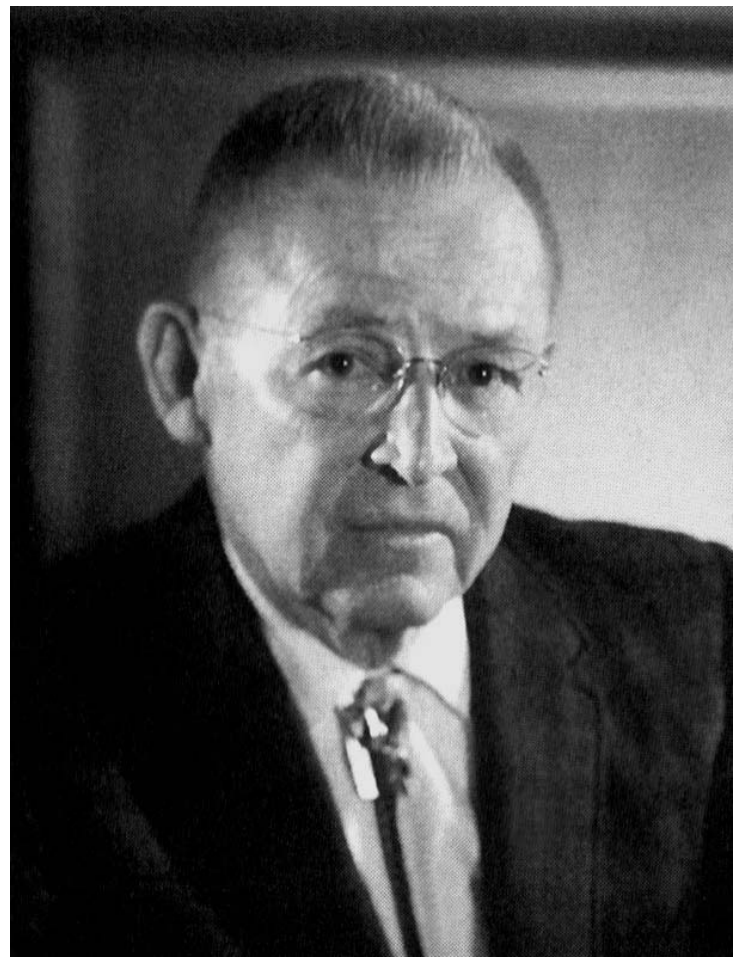

FIGURA 5 - Charles H. Tweed.

dentes. Essa convicção perdurou por aproximadamente mais 5 anos, pois, ao praticar a filosofia não-extracionista de Angle, observou que havia alcançado sucesso em apenas $20 \%$ dos pacientes ${ }^{45}$. Em 1936, ele publicou seu primeiro artigo sobre extrações de dentes com finalidade ortodôntica. Foi considerado um traidor pelos demais discípulos de Angle, sendo severamente criticado. Como resposta, intensificou ainda mais suas pesquisas. Em 1940, ele apresentou 100 casos clínicos num encontro da Angle Society, em Chicago. Apesar dos tratamentos com extrações dentárias terem alcançado alto grau de excelência, a platéia silenciou, pois Tweed havia violado o princípio sagrado de Angle. Somente Robert H. W. Strang, um dos primeiros alunos da Angle School, teve a coragem de cumprimentá-lo. Mais tarde, Tweed ensinaria sua técnica a Strang, que a praticou, ensinou-a e publicou-a em seu livro texto, Textbook of Orthodontia. Iniciou-se, então, uma verdadeira pere- 
grinação de ortodontistas a Tucson (Arizona) para fazerem o curso de Ortodontia ministrado por Tweed e seus assistentes. Assim, o aparelho Edgewise tornou-se universalmente conhecido ${ }^{46}$.

Assim como Tweed, o australiano Percy Raymond Begg (1898-1983) também era ex-aluno da Angle Scholl of Orthodontia. Durante o curso, teve permissão para tratar alguns casos com o braquete Edgewise. Em 1926, voltou à Austrália e passou a realizar os tratamentos tal como aprendera com Angle, ou seja, sem extrações. Sua insatisfação com a convexidade produzida nos perfis de alguns pacientes o incentivou a fazer desgastes nas faces interproximais dos dentes, a exemplo do que observara nos aborígenes australianos, ou mesmo refazer os casos com extrações de dentes. Em 1929, passou a utilizar o fio redondo nos braquetes do arco de canto, com o objetivo de reduzir o atrito. Em 1933, inverteu o braquete do arco de cinta da posição incisal para a gengival. Com essa experiência, compreendeu que poderia usar forças mais suaves, conseguindo que os dentes se movimentassem com maior rapidez. Além disso, reduziu também a largura do braquete do arco de cinta, mudança que o tornou conhecido pelo nome de Begg ${ }^{33}$.

Os primeiros cursos de pós-graduação em Ortodontia dentro de universidades norte-americanas foram abertos em 1922, nas Universidades de Nova York e Columbia, ambas na cidade de Nova York, e ambas oferecendo um ano inteiro de educação ortodôntica. Na Columbia, a coordenação era de Leuman M. Waugh (1877-1972), um ortodontista canadense autodidata, fundador da faculdade de Odontologia daquela instituição, e que também ajudou a fundar a International Association of Dental Research (1920). Quando Waugh era presidente da American Society of Orthodontists (ASO), em 1935, foi o responsável por organizá-la e transformá-la numa associação mais consistente ${ }^{51}$.

Um fato de destacada importância para a Ortodontia foi o advento da radiografia cefalométrica, desenvolvida por Broadbent (1884-1977) em
1931. Começaram a surgir, então, diversos estudos sobre o crescimento e o desenvolvimento das estruturas dentocraniofaciais e, conseqüentemente, as más oclusões provocadas por padrões de crescimento desfavoráveis puderam ser identificadas de forma mais acurada, auxiliando sobremaneira o ortodontista no diagnóstico, planejamento e prognóstico dos casos de má oclusão. O alemão Hofrath (1899-1952), em Düsseldorf, apresentou método semelhante, no mesmo ano de 1931, diferenciando-se daquele preconizado por Broadbent apenas quanto à técnica de obtenção das telerradiografias ${ }^{52}$.

Durante cinco anos, Broadbent acumulou uma quantidade considerável de películas cefalométricas, que incluía telerradiografias seriadas de 4.309 crianças de diferentes idades. Em 1937 ele publicou alguns resultados de suas pesquisas. A revelação mais extraordinária foi que a face das crianças normais se desenvolve para baixo e para frente ${ }^{11}$. Enquanto Broadbent colecionava radiografias de indivíduos com características de normalidade, Brodie, na Universidade de Illinois, utilizava o cefalostato para o estudo clínico. Em 1938, ele e seu grupo demonstraram que o sucesso do tratamento dependia de um crescimento facial adequado, era possivel movimentar dentes sem alterar suas inclinações axiais e que as modificações do tratamento ortodôntico pareciam ficar restritas ao osso alveolar, enterrando de vez a antiga crença de que seria possivel fazer o osso crescer $^{12}$.

A partir dos anos 60, começou a surgir nos Estados Unidos a idéia de se introduzir inclinações nos slots ou nas bases dos braquetes. O objetivo era minimizar o trabalho do operador, ao incorporar dobras precisas aos fios de metal - o que dependia do treinamento e da habilidade do ortodontista, muitas vezes sendo difícil de ser reproduzido nas trocas subseqüentes dos arcos. Lawrence F. Andrews denominou essa técnica como Straightwire, ou arco reto, em Português, descrevendo-a detalhadamente em 1976, apesar de procedimento semelhante ter sido proposto por Joseph R. Ja- 
rabak, em 1960. Também em 1976, Robert Murray Ricketts apresentou a técnica Bioprogressiva, considerada pelo autor uma evolução da técnica Edgewise, baseada na utilização de arcos leves e braquetes com slots pré-inclinados ${ }^{47}$.

No final dos anos 60, quando se tornou evidente que a colagem dos braquetes ortodônticos diretamente sobre o esmalte dentário era um procedimento viável, e braquetes de plástico e de porcelana já estavam sendo esperados, a utilização da superfície lingual dos dentes parecia ser a última fronteira estética. Em 1978, Fujita desenvolveu os braquetes linguais ou invisiveis. A técnica ganhou popularidade rapidamente no início dos anos 80 , mas, devido às dificuldades técnicas, particularmente nos estágios de finalização, foi descartada como técnica de rotina ${ }^{55}$.

Em 1986 surgiu o braquete Tip-edge, projetado por Peter Kesling a partir do braquete Edgewise convencional, no qual cunhas opostas ao slot foram removidas diagonalmente para permitir inclinação mesiodistal em direção pré-determinada. Inclinações em um único sentido foram incorporadas ao slot, e o torque incorporado à base do braquete $^{13}$. A partir de meados da década de 1990 tornaram-se viáveis os braquetes auto-ligantes (Speed system, Time bracket, Damon SL e Twinlock). Esses braquetes apresentam uma superfície de metal embutida que pode ser aberta e fechada, dispensando amarração ${ }^{24}$.

Verdadeiramente, todas essas técnicas se baseiam no mesmo princípio: no slot do braquete deverá ser encaixado um fio retangular, de dimensões transversais adequadas. E este foi o princípio preconizado por Angle ao desenvolver o braquete Edgewise.

\section{O ENSINO DA ORTODONTIA NO BRASIL}

A primeira referência oficial à Ortodontia, em nosso país, é datada de 1856 . O decreto $n^{\circ}$ 1.764 (14 de maio) versava sobre as matérias que o candidato a dentista deveria dominar, para que estivesse apto a receber o título de dentista apro- vado, junto à Faculdade de Medicina: "O exame dos dentistas versará sobre: 1) Anatomia, Fisiologia, Patologia e anomalias dos dentes, gengivas e arcadas alveolares; 2) higiene e terapêutica dos dentes; 3) descrição dos instrumentos que compõem o arsenal cirúrgico do dentista; 4) teoria e prática da sua aplicação; 5) meios de confeccionar as peças da prótese e Ortopedia dentária" (Cap. VII, Art. 81) ${ }^{10}$.

Apesar de tal exame ser ainda muito rudimentar, constitua um obstáculo ao charlatanismo e ao livre exercício da Odontologia. Era feito em bancas constituídas por médicos, que não possuíam conhecimentos sólidos da matéria, e por examinandos, cuja aprendizagem se fizera com dentistas, fora da faculdade, nada se exigindo como preparo básico, bastando ao candidato apresentar documentos que provassem a sua moralidade ${ }^{17}$.

Somente no final do século XIX é que se passou a dar mais atenção aos assuntos ligados à Odontologia, que começou a ser considerada necessária $^{34}$. No ano de 1884 surgiram os primeiros cursos, através do decreto no 9.311 (25 de outubro), anexos às Faculdades de Medicina do Rio de Janeiro e Bahia (onde só seria implantado em 1891, por motivos logísticos). O curso de Odontologia era constituído pelas seguintes matérias, divididas em três anos ou séries de exames: $1^{a}$ série - Física, Química Mineral e Anatomia Descritiva e Topográfica da Cabeça; $2^{a}$ série - Histologia Dentária, Fisiologia Dentária, Patologia Dentária, e Higiene da Boca; $3^{\text {a }}$ série - Terapêutica Dentária, Cirurgia e Prótese Dentária ${ }^{10}$.

Os formados recebiam o título de dentista, porém não assinavam seus diplomas, nem havia colação de grau ou outras formalidades, o que só passou a ocorrer a partir de 1893, ano em que obtiveram, também, o direito de se intitularem cirurgiões-dentistas ${ }^{17}$. Apesar dessas conquistas, o decreto $n^{\circ} 1.482$, de 24 de julho de 1893, acabou prejudicando a evolução do ensino odontológico no Brasil, pois, através de uma série de medidas, modificou a sistematização do curso, que teve, 
sem razão, suprimido um ano. Dessa forma, as matérias ficaram divididas em duas séries de exames: $1^{a}$ série - Anatomia Descritiva e Médico-cirúrgica da Cabeça, Histologia da Boca e Anexos, Fisiologia Dentária e Higiene Dentária; 2ª série: Patologia Dentária, Terapêutica Dentária, Prótese Dentária e Clínica Dentária ${ }^{10}$.

Finalmente, no dia 13 de janeiro de 1925, no governo de Arthur Bernardes, foi determinado pelo artigo 119 do decreto $n^{\circ} 16.782$, o seguinte: "Fica transformado em Faculdade de Odontologia, anexo à Faculdade de Medicina, o curso de Odontologia". O artigo 121 versava sobre as cadeiras que comporiam o curso, que seria feito em três anos, da seguinte forma: $1^{\circ}$ ano - Anatomia em geral e especialmente da boca, Histologia e Noções de Microbiologia, Fisiologia, Metalurgia e Química Aplicada; $2^{\circ}$ ano - Patologia Geral e Anatomia Patológica, especialmente da boca, Técnica Odontológica, Prótese ( $1^{\mathrm{a}}$ parte), Patologia e Clínica Odontológica; $3^{\circ}$ ano - Clínica Odontológica, Ortodontia e Prótese dos Maxilares, Higiene, especialmente da boca, e Terapêutica ${ }^{10}$.

Segundo o artigo 127, foram consideradas cadeiras privativas do curso de Odontologia, as seguintes: Metalurgia e Química Aplicada, Técnica Odontológica, Patologia e Clínica Odontológica, Prótese ( $\mathrm{l}^{\mathrm{a}}$ parte), Ortodontia e Prótese dos Maxilares. $\mathrm{O}$ artigo 128 determinou que os professores dessas cadeiras teriam o título de professores privativos. Mais tarde, em 1933, a Faculdade de Odontologia conquistaria sua autonomia, separando-se da Faculdade de Medicina (decreto $\mathrm{n}^{\circ}$ 23.512, de 28 de novembro), e os professores privativos passariam a ter a designação de professores catedráticos ${ }^{17}$.

De acordo com a resolução do Conselho Universitário de 20 de agosto de 1947, o curso da Faculdade Nacional de Odontologia passou a ter a duração de quatro anos, entrando em vigor a partir de 1948. Em 1968, com a reforma universitária, extinguiram-se as cadeiras e criaram-se os departamentos; no ano seguinte, o título de "professor catedrático" foi substituido pelo de "professor titular"34.

Do cotejo de todos esses decretos, observa-se que a Ortodontia passou por um longo período de ostracismo, pelo menos dentro do contexto do ensino oficial. De 1856 a 1884 foi cobrado dos candidatos ao exame de habilitação odontológica o conhecimento "das técnicas de confecção das peças da prótese e Ortopedia dentária”. Porém, a partir da instituição dos cursos de Odontologia, em 1884, até 1925, quando foi criada a Faculdade de Odontologia, a Ortodontia desapareceu dos currículos oficiais. Essa ausência merece ser analisada detalhadamente mais adiante.

Com respeito à pós-graduação, serão abordados os cursos considerados históricos, criados até a primeira metade da década de 70 do século passado. Baracchini ${ }^{9}$ e Freitas $^{20}$ relataram que o primeiro curso de especialização em Ortodontia foi iniciado em 1951, sob a coordenação do professor Arthur do Prado Dantas (1902-1968) (Fig. 6),

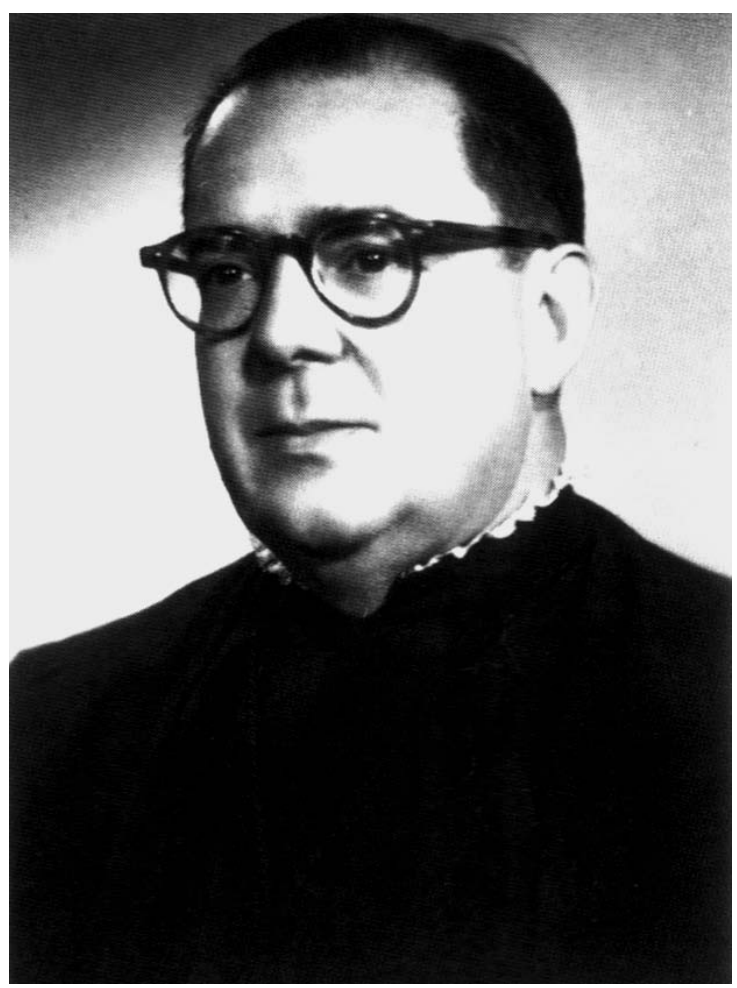

FIGURA 6 - Professor Arthur do Prado Dantas. 


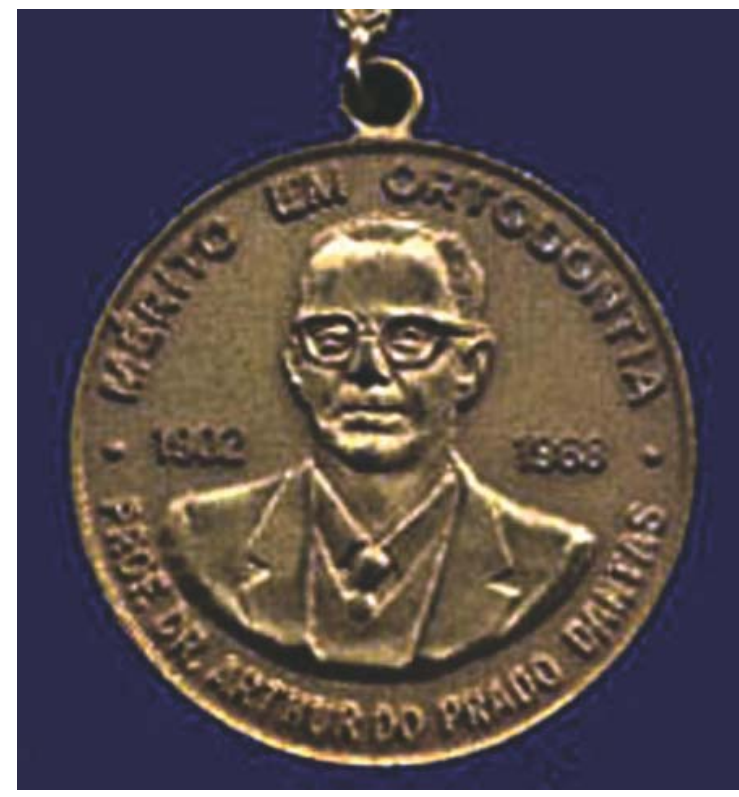

FIGURA 7 - Medalha "Arthur do Prado Dantas", criada em 1990 pela Sociedade Paulista de Ortodontia (SPO).

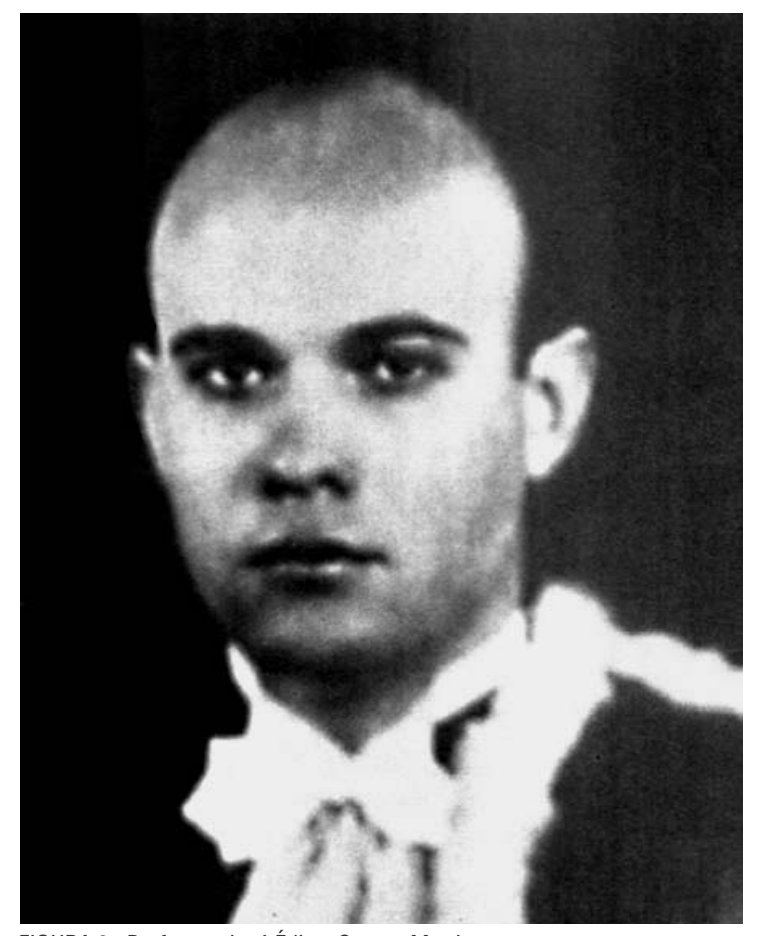

FIGURA 8 - Professor José Édimo Soares Martins. no Departamento de Ortodontia da Associação Paulista de Cirurgiões-Dentistas (APCD). O curso, com duração de dois anos, funcionou até 1955, e teve duas turmas formadas.

Natural da cidade de Santos/SP, Dantas graduou-se em Odontologia pela Faculdade de Farmácia e Odontologia da Universidade de São Paulo (atual Faculdade de Odontologia da USP), na qual também iniciaria, em 1938, sua carreira no magistério, na cadeira de Ortodontia. Obteve o título de Livre-Docente em 1940 e o de professor Catedrático em 1959. Tinha capacidade para abraçar diversas atividades ao mesmo tempo. No Serviço Dentário Escolar, localizado no Edifício Marrocos, no centro da cidade de São Paulo, era responsável pela orientação dos tratamentos na área de prevenção. Auxiliado pelo então estagiário Reynaldo Baracchini, em 1952 criou a Clínica de Ortodontia daquele Serviço, com o objetivo de atender crianças portadoras de anomalias dentárias, as quais recebiam cuidados nas dependências da USP. Pouco tempo mais tarde juntaram-se ao grupo Jairo Corrêa, Henio Eiras e Sebastião Interlandi. Em 1956, Dantas convidou Interlandi para auxiliá-lo também na cadeira de Ortodontia da Faculdade ${ }^{9}$. Em 1990, a Sociedade Paulista de Ortodontia (SPO) criou o Diploma e a Medalha Arthur do Prado Dantas, com a finalidade de agraciar personalidades que prestaram relevantes serviços à Ortodontia brasileira ${ }^{48}$ (Fig. 7).

Em 1956, Tobias Kant Coutinho Rothier (1925-2005) foi convidado pelo professor Aristeu Gonçalves Leite, então Diretor do Instituto de Odontologia da Pontifícia Universidade Católica (PUC) do Rio de Janeiro, a ministrar um curso de especialização em Ortodontia. Nos anos de 1956 a 1958 formaram-se 3 turmas, com 10 alunos cada. As aulas eram ministradas em seu próprio consultório, pois a instituição não possuía espaço físico adequado. Ao término da terceira turma, Tobias solicitou o seu desligamento da vida acadêmica, passando a dedicar-se exclusivamente à sua clínica particular. Em 2005 participou das solenidades 
comemorativas dos 50 anos de fundação da Sociedade Brasileira de Ortodontia (SBO) como derradeiro sócio-fundador ${ }^{39}$.

Em 1959 foi iniciado o primeiro curso de especialização em Ortodontia dentro de uma universidade brasileira. Foi criado na Faculdade Nacional de Odontologia da Universidade do Brasil, atual Faculdade de Odontologia da Universidade Federal do Rio de Janeiro (UFRJ), sob a coordenação do professor José Édimo Soares Martins (1915-1991)32 (Fig. 8).

Nascido na cidade mineira de Ponte Nova e graduado pela antiga Faculdade de Farmácia e Odontologia da Universidade de Minas Gerais (1936), Martins se transferiu para o Rio de Janeiro e foi nomeado professor assistente em 1937, dedicando-se, a partir desta data, inteiramente ao ensino da Ortodontia. Recebeu o título de Livre Docente em 1941 e o de Professor Catedrático no dia 9 de janeiro de 1948. Em 1950, obteve uma bolsa de estudos oferecida pela W. K. Kellog Foundation e seguiu para os Estados Unidos, onde fez um curso de pós-graduação em Ortodontia na Universidade de Washington. Quando regressou ao Brasil, em 1952, veio com o firme propósito de divulgar o que havia aprendido. Determinou que sua missão seria implantar as bases do ensino sério e estruturado da Ortodontia. O primeiro passo foi a preparação de seus assistentes. Começou ministrando aulas, em caráter informal, a alguns interessados, entre os quais os professores Hélio de Oliveira Fernandes, Carlos de Souza Telles e Antônio Carlos Peixoto da Silva. Depois foi preciso criar espaço físico para clínicas e laboratórios, que foram instalados nas dependências do antigo prédio onde funcionava a Faculdade, na Praia Vermelha, nos moldes da Universidade de Washington, em Seattle. Martins trouxe as plantas das bancadas, detalhes dos acessórios e criou-se um ambiente parecido ao da "Universidade Mãe"19.

Em 1974 o curso foi elevado ao nível de mestrado, reconhecido pela Universidade e pelo Conselho Federal de Educação (CFE). No segundo

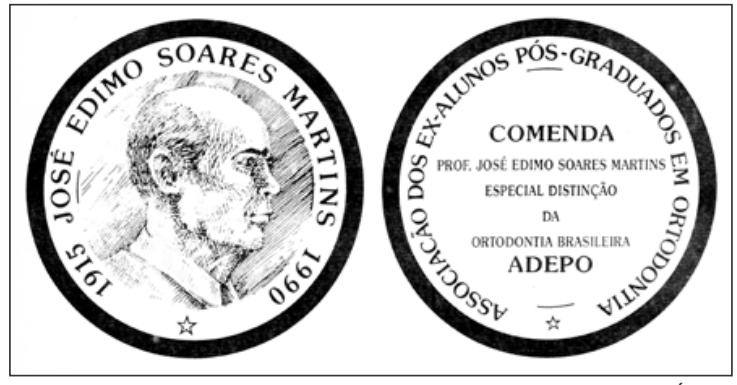

FIGURA 9 - Representação gráfica da Comenda "Professor José Édimo Soares Martins", criada pela ADEPO, em parceria com a SBO, em 1992.

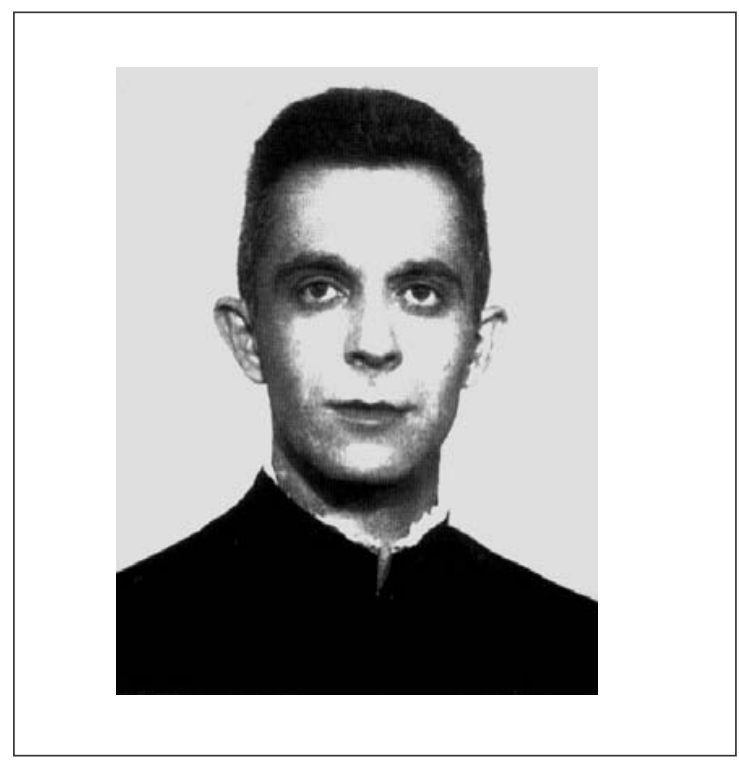

FIGURA 10 - Professor Manoel Carlos Müller de Araújo.

semestre de 1980, a Faculdade de Odontologia transferiu-se para a Ilha do Fundão, e o departamento ganhou novas instalações. Paralelamente, surgiu também uma situação nova, com a aposentadoria do professor Martins e a perda prematura do professor Hélio, em 1979. O professor Telles, então, assumiu a coordenação do curso. Em 1981, entrou em funcionamento o curso de doutorado em Odontologia, área de concentração em Ortodontia. Reconhecendo os relevantes serviços prestados pelo professor Martins ao ensino da Ortodontia, a Sociedade Brasileira de Ortodontia (SBO) 
outorgou-lhe, em 1985, o título maior de Patrono da Ortodontia Brasileira ${ }^{19}$. Em 1992, a SBO, em parceria com a Associação de Ex-Alunos PósGraduados em Ortodontia da UFRJ (ADEPO), criou a Comenda Professor José Édimo Soares Martins - Especial Distinção da Ortodontia Brasileira ${ }^{47}$ (Fig. 9).

Em 1962, o professor Manoel Carlos Müller de Araújo (Fig. 10) iniciou, na Faculdade de Odontologia de Piracicaba, o curso de especialização em Ortodontia, com cinco alunos matriculados. Naquela época, a Faculdade era um instituto isolado de ensino superior do Estado de São Paulo, e, atualmente, pertence à UNICAMP. Do ensino básico constava, principalmente, a filosofia de tratamento proposta por Tweed. Com o crescimento científico do corpo docente, em 1974 o curso foi reconhecido como mestrado pelo CFE. Em 1983 teve início a primeira turma do curso de doutorado, sob a coordenação do professor Darci Flávio Nouer ${ }^{31}$.

Em 1966, o professor Sebastião Interlandi tornou-se o primeiro coordenador do curso de especialização em Ortodontia da Faculdade de Odontologia da Universidade de São Paulo (USP). Ele havia retornado ao Brasil três anos antes (1963), após concluir o curso de mestrado nos Estados Unidos, na Universidade de Saint Louis (Missouri), ao qual, mais tarde, se juntaria o título de Livre Docente concedido pela USP (1968). O ensino básico abrangia a técnica Edgewise e informações sobre outras técnicas ortodônticas ${ }^{31}$. Em 1974 o curso foi credenciado junto ao Conselho Federal de Educação (CFE) como Mestrado em Odontologia, área de concentração em Ortodontia. Naquele mesmo ano, o professor Sebastião Interlandi concorreu a concurso público e alcançou o cargo de Professor Titular ${ }^{47}$. Atualmente são oferecidos cursos de mestrado e doutorado a cada dois anos.

$\mathrm{Na}$ Faculdade de Odontologia de Bauru da Universidade de São Paulo (FOB-USP) foi iniciado, em 1973, o curso de especialização em Ortodontia, sob a coordenação do professor Décio
Rodrigues Martins, especialista em Ortodontia pela Oregon Dental School (Portland). A aula inaugural foi ministrada no dia 2 de agosto daquele ano. Em 1980 Décio Martins defendeu tese e obteve o título de livre-docente. Em 1981 o curso foi credenciado como Mestrado em Odontologia, área de concentração em Ortodontia, junto ao Conselho Federal de Educação (CFE). O crescimento científico da Disciplina de Ortodontia da FOB deu origem também ao curso de doutorado, iniciado em 1982 e reconhecido em $1989^{47}$.

Por conseguinte, num espaço de tempo de menos de 15 anos (1959-1973), haviam quatro cursos de pós-graduação em Ortodontia em funcionamento no Brasil. Eles estavam (e ainda estão) localizados nas cidades do Rio de Janeiro, Piracicaba, São Paulo e Bauru. Foi decisiva a influência que esses cursos tiveram sobre o desenvolvimento da Ortodontia nacional. Eles formaram professores, pesquisadores, coordenadores, avaliadores, chefes de departamento, diretores, presidentes de associações e de entidades de classe. Em última análise, foram responsáveis não apenas por legarem à Ortodontia brasileira profissionais que se destacavam pela excelência clínica, mas, principalmente, por serem formadores de opinião em essência, que futuramente atingiriam outras regiões do país.

Nas dependências de dois desses cursos foram instalados os primeiros cefalostatos a operarem em território nacional. Em 1963 um cefalostato da marca Wemer foi montado e entrou em funcionamento na Praia Vermelha (Universidade do Brasil). Dois anos depois, um aparelho semelhante foi instalado no curso de especialização em Ortodontia da Universidade de São Paulo (USP).

\section{OS PRECURSORES NO BRASIL}

Em agosto de 1896 o professor Antônio Gonçalves Pereira da Silva (1851-1916) foi nomeado para reger a cadeira de Prótese Dentária do curso de Odontologia da Faculdade de Medicina do Rio de Janeiro. Ele era o terceiro professor contratado para aquele curso, e possuía o título de dentista 
aprovado pela Faculdade de Medicina (1870) ${ }^{17}$. Apesar da Ortodontia ser considerada a sub-especialidade menos prestigiosa da prótese, Pereira da Silva mostrava grande interesse pelo assunto, o que deveria parecer bastante incomum entre seus pares, até mesmo beirando a excentricidade. Afinal, quem estaria interessado em regularizar dentes no Brasil, naqueles primeiros anos da recém proclamada república?

O fato é que, seis anos antes, na sessão realizada no dia 5 de março de 1890 no Instituto dos Cirurgiões-Dentistas do Rio de Janeiro (fundado em 1889), ele havia levado um caso de fenda palatina para ser debatido com os colegas ${ }^{17}$. Talvez a dificuldade do tratamento deste defeito congênito o tenha inspirado e incentivado a se insinuar pelo caminho da Ortodontia. Em 1901 ele publicou dois artigos cujo tema era os aparelhos ortodônticos: Prótese dentária I - aparelhos ortodônticos em geral e suas diferentes modificações até hoje em uso para a substituição dos dentes naturais; e ainda, Prótese dentária II - descrição, construção e aplicação dos diversos aparelhos ortodônticos conhecidos.

Por certo, pelo menos alguns dentistas deviam estar interessados.

Carlos de Almeida Lustosa (1881-1937) (Fig. 11) recebeu o título de cirurgião-dentista no dia 31 de janeiro de 1903. Ele formou-se pelo curso de Odontologia da Faculdade de Medicina do Rio de Janeiro e, portanto, era um dos ex-alunos de Pereira da Silva, com quem estudou em 1902. Foi também o primeiro profissional a praticar a Ortodontia como especialidade no Brasil ${ }^{47}$.

Nascido em São João del Rei (MG), era irmão do dentista Paulo de Almeida Lustosa, inventor e fabricante da Cera Dr. Lustosa, muito utilizada na primeira metade do século XX para o alívio da dor de dente. Solteiro e sentindo forte necessidade de expandir seus conhecimentos para além daqueles adquiridos no curso de graduação, ele embarcou pela primeira vez para os Estados Unidos em 1910, quando teve oportunidade de participar de um curso de atualização em diversas especialidades odontológicas, com duração de 2 anos, na Universidade da Filadélfia ${ }^{39}$.

Ao retornar ao Brasil, em 1912, manteve-se atualizado por meio dos periódicos científicos que assinava. Desta forma, tomou conhecimento de alguns dos primeiros aparelhos ortodônticos preconizados por Edward Hartley Angle. Com os ensinamentos primários obtidos através dessas publicações, iniciou alguns casos clínicos. Ao questionar-se sobre os resultados alcançados, concluiu que seria indispensável passar por um período de aprendizagem maior. No início dos anos $20 \mathrm{em}-$ barcou novamente para os Estados Unidos, com o objetivo de se inscrever no curso de Ortodontia. Entretanto, seu primeiro contato com Angle, em Pasadena, na Califórnia, foi decepcionante. Alegando que Lustosa não possuía o conhecimento de matérias básicas, tais como Anatomia, Embriologia e Histologia, que considerava essenciais para o bom aproveitamento do curso, ele negou-lhe

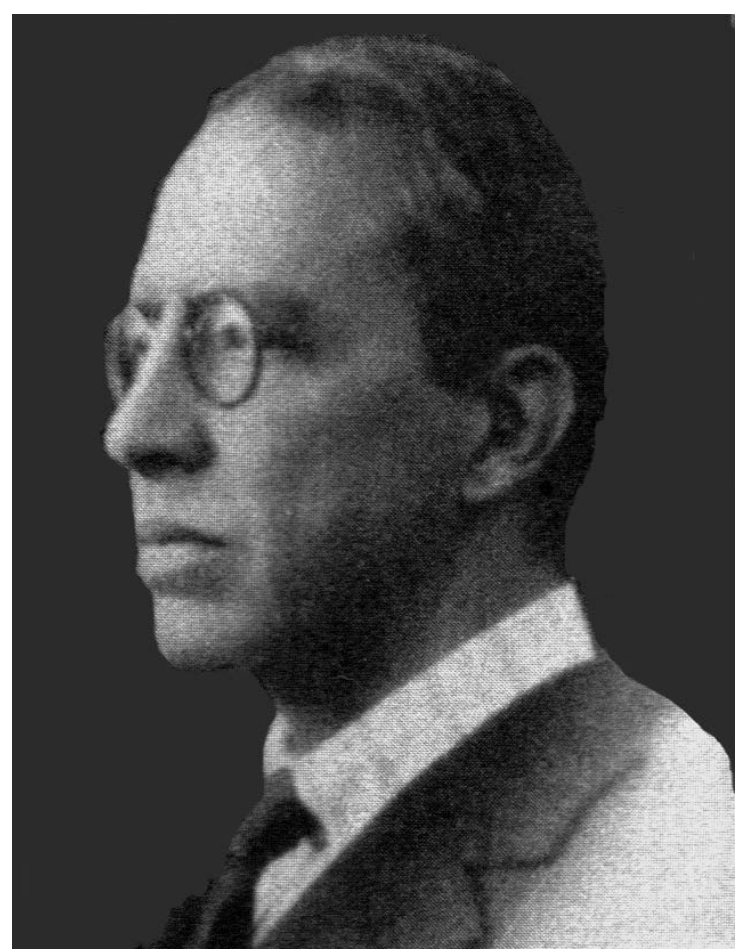

FIGURA 11 - Carlos de Almeida Lustosa. 
a matrícula. Lustosa não desistiu, procurou por Harvey Stallard, que o havia apresentado a Angle, e dele obteve a promessa de ensinar-lhe esses fundamentos, de modo a prepará-lo para o curso. Após estagiar durante um ano no consultório particular de Stallard, na cidade de San Diego (Califórnia), apresentou-se novamente e desta vez foi aceito na Angle School of Orthodontia. Concluiu o curso em 1923 (Fig. 12). A técnica que passou a empregar foi a do arco de cinta (ribbon arch) ${ }^{47}$.

Pouco depois de sua volta ao Brasil, Lustosa ficou gravemente enfermo, sendo obrigado a se afastar para tratamento de saúde. Durante este período, trabalhou na elaboração de um livro, que publicou em 1924 - "A Orthodontia e a creança" - dirigido aos encarregados de zelar pela educação infantil $1^{15}$. Na publicação, procurou transmitir princípios básicos de Ortodontia preventiva e enumerar as condições ideais para uma boa oclusão. Dedicou a obra a Harvey Stallard, como "tributo de admiração pelo seu belo talento". Era um trabalho pioneiro que, apesar de muito simples, pôde alcançar os objetivos aos quais se propunha. No prefácio, a Ortodontia é descrita como "... um assunto novo no nosso meio e a muita gente parecerá pueril o que uma longa observação nos Estados Unidos, principalmente na Califórnia, demonstrou cabalmente, ser de suma importância para os dentes e para a saúde em geral" ${ }^{129}$.

Nesta época, ele mudou seu consultório, originalmente na Rua da Assembléia, para o Largo da Carioca (Fig. 13, 14), ambos localizados no Centro do Rio de Janeiro, adaptando-o para o exercício da Ortodontia. No novo endereço foi auxiliado por Kant Rothier Duarte (1899-1963) e iniciou na carreira seu sobrinho, Delfino Magalhães Lustosa (1910-1991), estudante de Odontologia ${ }^{47}$. Em 1932 publicou outro trabalho, denominado "Algumas causas das maloclusões dentárias", no qual teceu considerações sobre a etiologia de diversos tipos de má oclusão. A composição da obra ficou, como da outra vez, a cargo da Typographia Leuzinger, empresa de propriedade de sua família ${ }^{30}$.

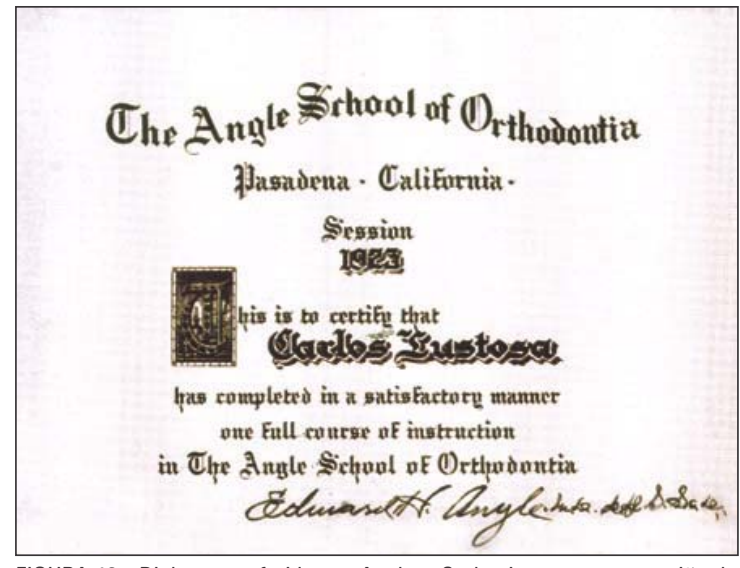

FIGURA 12 - Diploma conferido por Angle a Carlos Lustosa, por ocasião do término do curso da Angle School of Orthodontia.

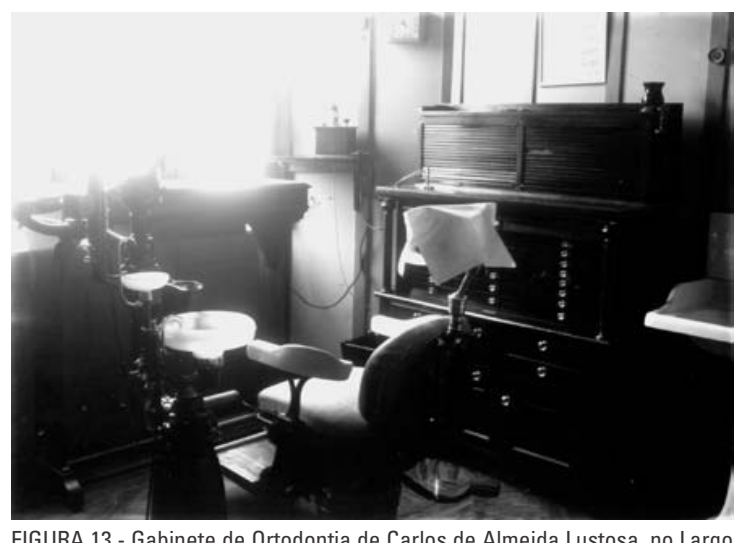

FIGURA 13 - Gabinete de Ortodontia de Carlos de Almeida Lustosa, no Largo da Carioca.

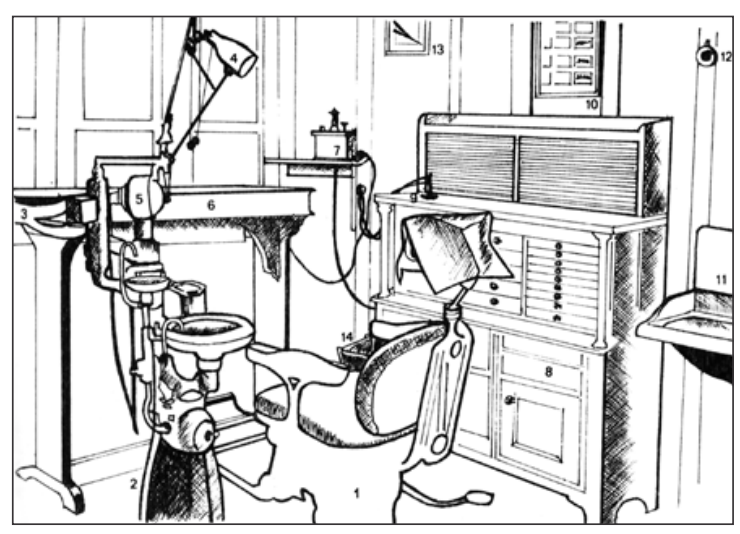

FIGURA 14 - Esquema gráfico do consultório: 1) cadeira odontológica da marca Wilkerson, modelo 1905; 2) cuspideira S.S. White Pedestal Cuspidor; 3) bandeja; 4) refletor; 5) motor de corda com haste e caneta; 6) bancada de trabalho, com 1,20m de altura (os dentistas trabalhavam de pé); 7) máquina de solda-a-ponto da marca Rock Mountain D. P. Co.; 8) armário com gavetas; 9) maçarico (ar e gás); 10) gravura da seqüência de erupção dentária; 11) lavatório; 12) termômetro; 13) relógio; 14) lixeira. 
Lustosa exerceu a Ortodontia até o final de 1937, quando faleceu, vítima de um atropelamento no Largo da Glória, fato bastante noticiado pela imprensa carioca. Em conseqüência, Kant Rothier Duarte assumiu a direção da clínica ${ }^{39}$.

Dentro do contexto observado no Brasil do final do século XIX e início do século XX, não seria exagerado supor a existência de profissionais que, concomitantemente com a clínica odontológica, executassem também alguns procedimentos ortodônticos. Tanto assim que, em 1928, Alberto F. Gomes intitulava-se especializado em "Orthodontia e pontes", atendendo em consultório particular localizado no centro da cidade de São Paulo ${ }^{26}$.

A partir 1937, Kant Rothier começou a treinar dentistas para ajudá-lo na clínica. Criou um centro particular de formação de ortodontistas, uma vez que ainda não havia curso de pós-graduação no Brasil. Convidou para fazer parte da equipe José Schmidt Sobrinho, em 1937, Delfino Magalhães Lustosa e Spencer Rothier Duarte, ambos em 1938, Armando Werneck de Carvalho, em 1943, e Tobias Kant Coutinho Rothier, em 1948 ${ }^{47}$.

Joaquim Bezerra Cavalcanti também praticava a Ortodontia no Rio de Janeiro, nos anos 30. Ele se aperfeiçoara nos Estados Unidos, na Temple University, com Robert Strang, e mantinha consultório particular no Edifício Odeon, no centro da cidade. No final daquela mesma década, Newton Rabello de Castro (1919-1999) começou a se interessar pela especialidade. Em 1940 ele acompanhou o trabalho de Kant Rothier em sua clínica particular. Em seguida, viajou para Buenos Aires (Argentina), onde estagiou com Armando Monti. Em 1944 fez um curso de Ortodontia na Northwestern University, em Chicago (Estados Unidos). Moacyr Rutowitsch começou seus estudos em Ortodontia na Argentina, em 1942, estagiando com Edmundo Locchi, Raul Otaño Antier e Olaviega. Mais tarde, em 1954, concluiu o curso da Temple University ${ }^{39}$.

Em Porto Alegre, Admar Raupp Terra (1920-2003) (Fig. 15) formou-se em Odontolo-

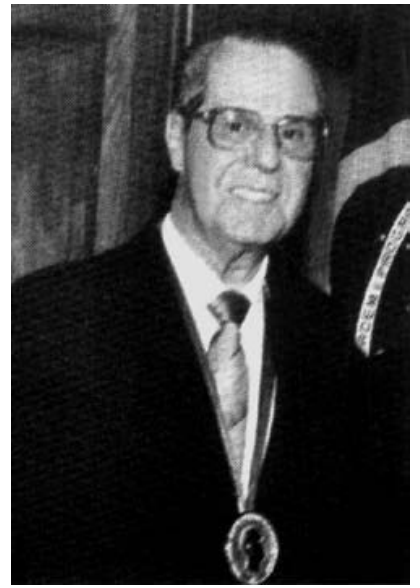

FIGURA 15 - Doutor Admar Raupp Terra, em 1994, homenageado com a Comenda "Professor José Édimo Soares Martins", em Caxambu (MG).

gia em 1943 e logo se interessou pelos assuntos ligados à Ortodontia. Em 1947 estagiou na clínica do professor Oscar Aldecoa, em Montevidéu (Uruguai), considerado, na época, um dos maiores centros de Ortodontia da América Latina. Em seu consultório particular tratou mais de 2.000 pacientes e, apesar de nunca ter estado oficialmente ligado ao ensino, enfatizava a importância da formação acadêmica. Era considerado um verdadeiro mestre, por estar sempre disposto a disseminar conhecimentos, fosse assistindo, promovendo ou ministrando cursos. Procurou orientar quem almejava a iniciação ortodôntica, organizou grupos de estudo e apoiou e incentivou a fundação da Sociedade Gaúcha de Ortodontia (SOGAOR). Devido, em grande parte, à sua liderança moral, ocorreu um crescente interesse pela Ortodontia no Rio Grande do Sul. Como conseqüência, em 1976 teve início o curso de Especialização da Faculdade de Odontologia da Universidade Federal do Rio Grande do Sul (UFRGS), sob a coordenação do professor Manoel F. Sanchez. Em 1985, Terra recebeu da SOGAOR o título de Patrono da Ortodontia Gaúcha ${ }^{35}$.

$\mathrm{Na}$ década de 1950 retornaram ao Brasil alguns profissionais que concluíram cursos de pósgraduação em Ortodontia no exterior. Em 1951 Armando O. Petersen Tavares voltou para Porto 
Alegre com o título de especialista concedido pela Columbia University (Nova York) ${ }^{47}$. Em São Paulo chegaram Paulo Affonso de Freitas, especialista pela Universidade da Pennsylvania ${ }^{20}$, além de Álvaro Rubem Marcondes e Carlos Jorge Vogel, pós-graduados pela Universidade de Illinois. Em 1963 Kurt Faltin Jr. foi o primeiro brasileiro a defender tese de doutoramento, na Universidade de Bonn ${ }^{31}$.

A expansão do ambiente científico acabaria por determinar rápidas transformações no meio ortodôntico. Em São Paulo, o Departamento de Ortodontia da Associação Paulista de CirurgiõesDentistas (APCD) patrocinou, de 4 a 7 de novembro de 1957, a I Semana Paulista de Ortodontia (Fig. 16). A despeito de ter sido o primeiro evento do gênero a se realizar no Brasil e organizado sem experiências prévias, acabou se transformando num marco relevante da Ortodontia brasileira. Admar Raupp Terra ficou encarregado de proferir o discurso de encerramento, e nele afirmou vislumbrar naquele momento "... a arrancada científica da Ortodontia em nosso país"31.

A I Semana Piracicabana de Ortodontia aconteceu de 1 a 6 de julho de 1963. O evento teve a presidência de Manoel Carlos Müller de Araújo e contou com a colaboração da recém reestruturada Sociedade Paulista de Ortodontia (ver adiante) ${ }^{31}$.

É importante entender que a evolução da Ortodontia ocorreu de forma diferente nos estados do Rio de Janeiro e de São Paulo. Até 1960 a cidade do Rio de Janeiro era a sede do Distrito Federal. Naquele ano, a capital foi transferida para Brasília e criou-se a figura da cidade-estado: a cidade do Rio de Janeiro passou a ocupar o mesmo território do recém criado Estado da Guanabara. Enquanto isso, o antigo Estado do Rio de Janeiro, cuja capital era a cidade de Niterói, apresentava um crescimento muito limitado, principalmente no seu interior, ao contrário do que acontecia no interior paulista. Em 1975 ocorreu a fusão dos dois estados, dando origem ao atual Estado do Rio de Janeiro, cuja capital passou a ser a cidade do

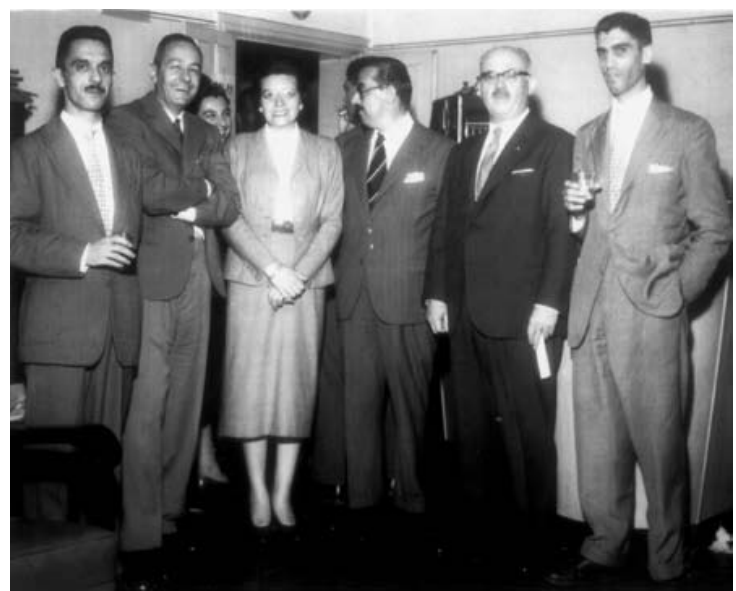

FIGURA 16 - Participantes da I Semana Paulista de Ortodontia. Da esquerda para a direita: Manoel Carlos Müller de Araújo (secretário), Raul Otaño Antier (conferencista), Pilar Ostivar (comércio de material ortodôntico), Fernando Archain (conferencista), José Mayoral (conferencista) e Paulo Affonso de Freitas (presidente).

Rio de Janeiro (Lei Complementar $n^{\circ} 20$, de $1^{\circ}$ de julho de 1974) ${ }^{22}$. Esses fatos ajudam a explicar porque o desenvolvimento da Ortodontia se deu de forma tão centralizada e dogmática no Rio de Janeiro, enquanto em São Paulo ocorreu uma tendência muito mais cosmopolita e descentralizadora, com a criação de vários centros de ensino no interior do estado. Aos cursos de Piracicaba e Bauru vieram se unir os de Araçatuba (Sociedade Paulista de Ortodontia, 1976), coordenado pelo professor Carlos Augusto Aranha Nunes Galvão; São Bernardo do Campo (Instituto Metodista de Ensino Superior, nível de mestrado, 1981) sob a coordenação do professor Júlio Wilson Vigorito, Araraquara (Faculdade de Odontologia de Araraquara - UNESP, 1982) coordenado pelo professor Tatsuko Sakima (em 1990 teria início o mestrado e em 1993 o doutorado, ambos sob a coordenação do professor Dirceu Barnabé Ravelli) e Bragança Paulista (Faculdade de Odontologia da Universidade São Francisco, 1984) coordenado pelo professor Miguel Neil Benvenga ${ }^{47}$.

No Rio de Janeiro, até meados dos anos 80 , os cursos de pós-graduação continuavam restritos à capital: em 1974 o curso de especialização da Po- 
liclínica Geral do Rio de Janeiro, coordenado pelo professor Cyro Ribeiro de Moura, pioneiro no ensino da técnica de Begg, foi credenciado pelo Conselho Federal de Odontologia (CFO). Em 1980 foi iniciado o curso de especialização em Ortodontia da Faculdade de Odontologia da Universidade do Estado do Rio de Janeiro (UERJ), sob a coordenação do professor Antônio Carlos Peixoto da Silva ${ }^{47}$ (em 1998 e 2004 foram disponibilizados os cursos de mestrado e doutorado, respectivamente, com área de concentração em Ortodontia). Além desses, o curso idealizado pelo professor José Édimo Soares Martins na UFRJ estava em atividade desde 1959.

\section{A LITERATURA ORTODÔNTICA BRASILEIRA}

Uma questão relevante é quais fontes de referência estavam disponíveis para os profissionais da primeira metade do século XX. A influência decisiva que Edward Hartley Angle exerceu sobre o desenvolvimento da Ortodontia mundial só fezse sentir mais acentuadamente, no Brasil, a partir de meados da década de 1920. Até então, Ortodontia ainda não existia como disciplina do curso de Odontologia e o empirismo dominava a prática ortodôntica ${ }^{47}$. Informações sobre a especialidade eram obtidas em compêndios originários da França ou dos Estados Unidos, de autores como Paul Dubois e Chapin Harris, entre outros ${ }^{17}$.

Até 1880 não havia uma única publicação em língua portuguesa que esclarecesse os assuntos referentes à Odontologia. Nesse ano, a Casa Cardoso, de Cardoso e Cia., estabelecida com artigos de cirurgia geral e dentária à Rua da Quitanda, $n^{\circ}$ 86, na cidade do Rio de Janeiro, resolveu mandar editar o "Manual do Dentista", organizado por Veridiano de Carvalho. Com pouco mais de duzentas páginas, a obra estava baseada no tratado de autoria de Chapin Harris. Dividia-se em quatro partes, nas quais eram estudados assuntos concernentes à Anatomia, Patologia e Terapêutica, Cirurgia, Mecânica e Prótese Dentária, prestando enorme auxílio a dentistas e estudantes ${ }^{17}$.
Em 1900, o professor Augusto Coelho e Souza (1863-1949) publicou o "Manual Odontológico", com 207 páginas de texto, abrangendo assuntos de Patologia Dentária, Terapêutica e Matéria Médica. O livro alcançou enorme sucesso, tanto no meio acadêmico quanto profissional. Em 1905 surgiu a segunda edição do manual. Ampliado, compreendia 397 páginas, incluindo capítulos sobre Prótese Dentária e Higiene ${ }^{47}$. Na terceira edição, publicada em 1910, o compêndio foi dividido em três volumes. Coelho e Souza contava agora com a colaboração do professor Antonio Dias de Carvalho, responsável pela parte referente à clínica odontológica. O capítulo XII do terceiro volume (Secção III) do manual apresentava o seguinte título: "Orthodontosia. Indicação dos aparelhos". O autor descreveu alguns tipos de má oclusão e os aparelhos ortodônticos que poderiam ser utilizados na clínica ${ }^{41}$. Na quinta edição, publicada em 1917, Coelho e Souza utilizou pela primeira vez o termo "Orthodontia" como título, cabendo esta parte ao livro dedicado à prótese dentária ${ }^{43}$. Nas edições seguintes, o texto permaneceu praticamente inalterado. Porém, quando veio a público a oitava edição, em 1938, tal capítulo já não constava mais das páginas do manual ${ }^{44}$.

Em 1939 seria publicado o primeiro livro-texto inteiramente dedicado à Ortodontia escrito por um brasileiro: "Ortodontia", de autoria de Carlos Alves da Costa, professor Catedrático de Ortodontia e Odontopediatria da Escola de Odontologia anexa à Faculdade Fluminense de Medicina (atual Faculdade de Odontologia da Universidade Federal Fluminense). De acordo com o autor "... o intuito primordial foi o de auxiliar os iniciados em Ortodontia, facilitando-os um compêndio escrito em nosso idioma". Realmente, o livro não trazia nenhuma inovação, tratando-se, isto sim, de cuidadosa compilação de trabalhos de diversos autores norte-americanos e europeus, os quais foram adaptados para o programa de ensino das escolas brasileiras de Odontologia ${ }^{16}$. Muitos dentistas tiveram o primeiro contato com a Ortodontia atra- 
vés desta obra, que durante mais de três décadas constituiu a única fonte de informação sobre os assuntos ortodônticos, pois somente em 1977 surgiria o segundo livro-texto escrito em Português "Ortodontia: bases para a iniciação" - coordenado e traduzido pelo professor Sebastião Interlandi ${ }^{27}$. Nos anos 80, com o crescente interesse pela Ortodontia, foram publicados mais de uma dezena de novos títulos, abrangendo os diversos campos da especialidade.

\section{A INDÚSTRIA ORTODÔNTICA NACIONAL}

Até meados da década de 1950, os ortodontistas brasileiros encontravam sérias dificuldades para obter o material necessário para a execução do tratamento ortodôntico. Era necessário fazer um pedido por carta, endereçado a algum fabricante do setor. Muitos exigiam um valor mínimo por pedido, sendo o material enviado pelo correio. A alternativa era a confecção da própria aparelhagem, o que dependia de habilidade e da disponibilidade de tempo por parte do profissional ${ }^{47}$.

Em 1954, a comerciante argentina Pilar Ostivar radicou-se na cidade de São Paulo, aí estabelecendo firma pioneira de importação de material ortodôntico, denominada Brasil Orthodontic Ltda. Esta firma representava a Unitek Corporation (EUA) no Brasil, vindo de encontro ao anseio dos ortodontistas, que passaram a adquirir o material ortodôntico com maior facilidade. Pouco tempo depois, a Dental Gaúcho também começaria a comercializar produtos dos fabricantes Dentaurum (Alemanha) e Rock Mountain (EUA). Porém, as taxas alfandegárias oneravam demasiadamente os produtos, o que, por sua vez, tornava o tratamento dispendioso e inacessivel para grande parte da populaçãa ${ }^{47}$.

No início dos anos 70, no entanto, Humberto Paes começou a produzir algum equipamento ortodôntico, na cidade do Rio de Janeiro. Eram cortadores de gesso, máquinas de solda a ponto, maçaricos e polishers, que passaram a ser comercializados pela Brasil Orthodontic. Tão empolgado e confiante se encontrava este pioneiro da indús- tria ortodôntica nacional, que resolveu emprestar seu próprio nome ao material que estava sendo fabricado - HUMPA. A ele se juntaram Otávio da Silveira, de Campinas, com a fabricação do cefalostato de Margolis e máquinas de solda a ponto, e Waldemar, na Vila Efigênia (periferia de São Pau1o), que fabricava alguns alicates ortodônticos ${ }^{47}$.

Inicialmente, a produção era quase artesanal, mas suficiente para abastecer o pequeno mercado consumidor de então, composto pelos ortodontistas que haviam feito curso no exterior e por aqueles formados nos cursos de pós-graduação das faculdades do Rio de Janeiro, Piracicaba, São Paulo e, posteriormente, de Bauru. Os ortodontistas cariocas podiam adquirir esses produtos através de Stelio Ribeiro da Silva, que representava a Brasil Orthodontic no Rio de Janeiro. Com a expansão do mercado, impulsionada pela abertura de diversos novos cursos de pós-graduação, foi construída uma fábrica da empresa em Santo André (SP), depois transferida para a capital do estado, cuja produção estava voltada para a fabricação de coroas metálicas e bandas ortodônticas. Nesse novo momento constituiu-se uma sociedade anônima, cujas ações foram vendidas, inclusive, para alguns ortodontistas. Esta fase estendeu-se até o início dos anos 80 , quando a empresa encerrou suas atividades. Nessa época surgiram vários novos fabricantes de material ortodôntico, especialmente no estado de São Paulo, que preencheram o espaço deixado pela Brasil Orthodontic ${ }^{47}$.

\section{AS ASSOCIAÇÕES DE CLASSE}

As sociedades e associações ortodônticas tiveram e continuam tendo grande importância para o desenvolvimento da Ortodontia brasileira, pois, através delas, tornou-se possível a difusão dos conhecimentos desta área no Brasil. Também acabaram incentivando estudos e pesquisas ortodônti$\cos ^{47}$. Entretanto, até o início da década de 50 do século passado existiram apenas tentativas esporádicas e frustradas de se congregar ortodontistas em torno de uma associação. Na segunda metade 
da década de 40, foi fundada, na cidade do Rio de Janeiro, uma entidade com o nome de Sociedade Brasileira de Ortodontia. Como não houve um rigor maior na seleção dos sócios, alguns deles não eram ortodontistas e sim dentistas clínicos. A diretoria foi formada por Joaquim Bezerra Cavalcanti (presidente), Kant Rothier Duarte (vice-presidente) e Virgílio Moojen de Oliveira (secretário). Este último era professor catedrático de prótese da Faculdade de Odontologia da Universidade do Brasil (atual UFRJ). Devido à divergência de interesses de seu quadro social, esta sociedade acabou encerrando suas atividades prematuramente ${ }^{39}$.

\section{Sociedade Brasileira de Ortodontia}

Um grupo de especialistas começou a elaborar um estatuto para uma nova Sociedade Brasileira de Ortodontia, que seria criada em 1955. O objetivo era estabelecer regras mais bem definidas, para que outros interesses não a desviassem do objetivo para o qual estava sendo instituída: divulgar o conhecimento ortodôntico técnico-científico no Brasil ${ }^{39}$

Naquela época, existiam quatro grupos que praticavam a Ortodontia no Rio de Janeiro. Eram liderados por Kant Rothier Duarte, Newton Rabello de Castro, ambos em clínicas particulares, Moacyr Ruthowitsch, na Policlínica Geral do Rio de Janeiro, e José Édimo Soares Martins, na Faculdade de Odontologia da Universidade do Brasil. Esses grupos atuavam isoladamente e não praticavam intercâmbio de conhecimentos ${ }^{47}$.

Entretanto, estava claro que era necessário criar uma entidade que catalisasse o ideal de todos eles. Moacyr Rutowitsch, que também treinava seus assistentes na Policlínica Geral do Rio de Janeiro, tomou a iniciativa de convidar os outros três grupos para formarem um centro de estudos, o que contribuiu para fortalecer a idéia de fundar uma sociedade. De fato, no dia 18 de agosto de 1955 foi fundada, no Rio de Janeiro, a primeira entidade de especialistas em Ortodontia do Brasil, a Sociedade Brasileira de Ortodontia (SBO). Sua primeira

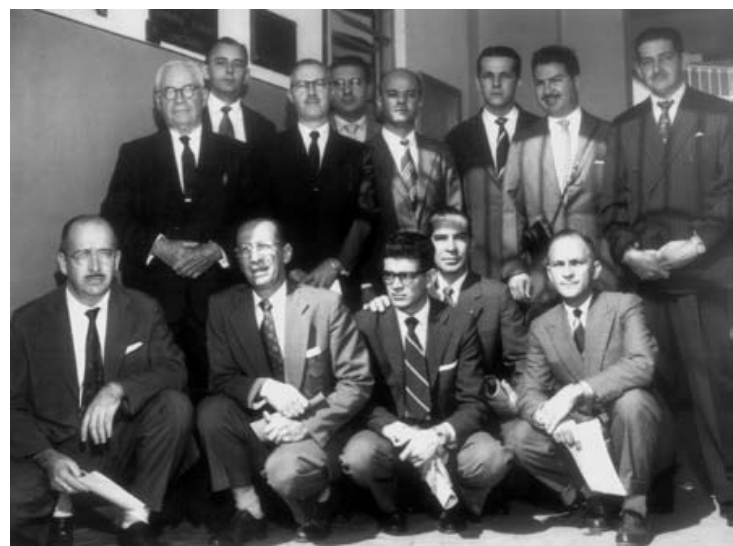

FIGURA 17 - Participantes do curso ministrado pelo Dr. Robert Strang, em 1958. Da esquerda para a direita, em pé: Robert Strang, Roberto Rocha, Cyro Ribeiro de Moura, Armando Werneck de Carvalho, José Édimo Soares Martins, Carlos de Souza Telles, Lineu Marcondes da Silva e Moacyr Rutowitsch. Agachados: Odilon Frossard de Souza, Spencer Rothier Duarte, Antônio Carlos Peixoto da Silva, Delfino Magalhães Lustosa e Hélio de Oliveira Fernandes.

diretoria esteve assim constituída: Moacyr Rutowitsch (presidente), Kant Rothier Duarte (vicepresidente), Newton de Castro (primeiro secretário), Armando Werneck de Carvalho (segundo secretário), Tobias Kant Rothier (tesoureiro) e José Édimo Soares Martins (diretor científico) ${ }^{39}$.

Desde então, a SBO trouxe para o Rio de Janeiro os mais expressivos nomes da Ortodontia mundial. Um dos primeiros cursos foi ministrado por Robert H. W. Strang, em 1958 (Fig. 17). Sua grande repercussão facilitou a vinda de outros expoentes da Ortodontia norte-americana e mundial ao Brasil. Atualmente, a Sociedade Brasileira de Ortodontia, juntamente com a Associação Brasileira de Ortodontia (ABOR), representa os ortodontistas brasileiros junto à World Federation of Orthodontists ${ }^{4}$. No dia 18 de agosto de 2005 a SBO comemorou 50 anos de existência, com a presença de vários palestrantes estrangeiros.

\section{Sociedade Paulista de Ortodontia}

Em São Paulo, no dia 4 de dezembro de 1959, foi fundada, extra-oficialmente, a Sociedade Paulista de Ortodontia (SPO). O seu primeiro presidente foi Oswaldo A. Mesquita Sampaio, tendo 
como secretário Manoel Carlos Müller de Araújo. Porém, no dia 2 de outubro de 1962 realizou-se uma Assembléia Geral Extraordinária, para definir o destino da entidade. Por unanimidade, votouse a continuidade do funcionamento da SPO em toda a sua plenitude. Também por unanimidade, foi destituída a diretoria, sendo nomeada uma

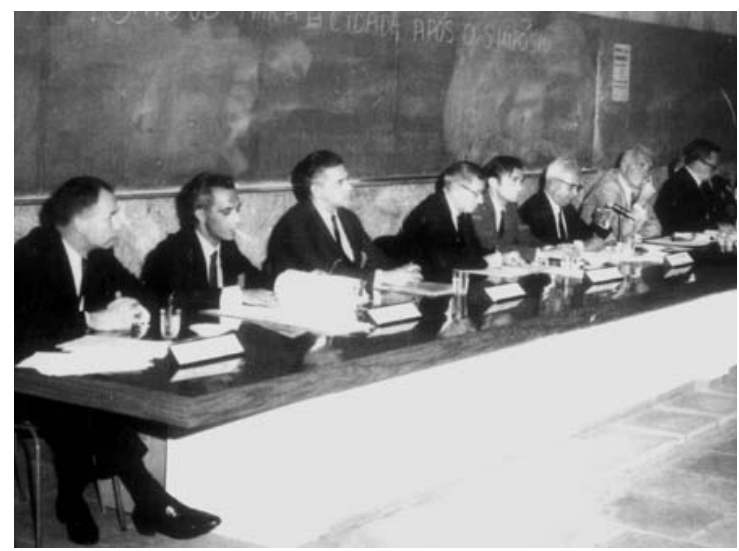

FIGURA 18 - Participantes do simpósio Educação Ortodôntica em cursos de Graduação e Pós-graduação, realizado durante o I Congresso Paulista de Ortodontia, em 1968. Da esquerda para a direita: Ernest H. Hixon, Manoel Carlos Müller de Araújo, Sebastião Interlandi, Allan G. Brodie, Carlos Jorge Vogel, Francisco Degni, Hector A. Tarasido, Quentin M. Ringenberg e José Édimo Soares Martins.

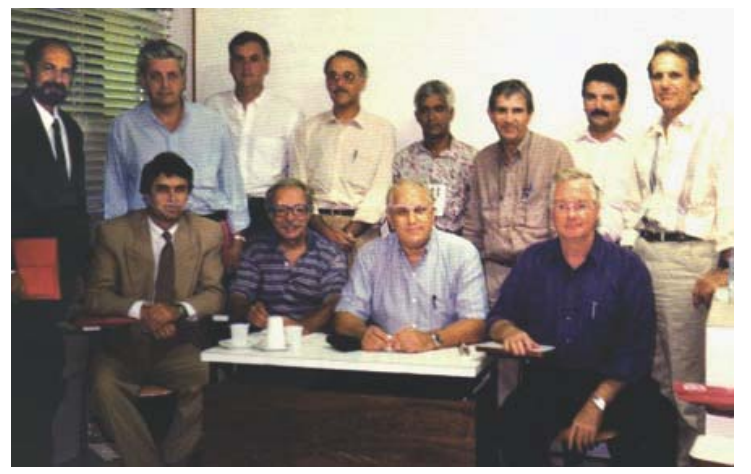

FIGURA 19 - Fotografia da fundação da ABOR. Da esquerda para a direita sentados: Gerson I. Köhler (Sociedade Paranaense de Ortodontia), Jairo Corrêa (Sociedade Paulista de Ortodontia), Eros Petrelli (Sociedade Paranaense de Ortodontia), Kurt Faltin Jr. (Grupo Brasileiro de Professores de Ortodontia e Odontopediatria). Em pé: Régis Rizzato (Sociedade Gaúcha de Ortodontia), Eustáquio Araújo (Sociedade Mineira de Ortodontia), Luciano Carvalho (Grupo Brasileiro de Professores de Ortodontia e Odontopediatria), Deocleciano Carvalho (Sociedade Paulista de Ortodontia), Luis Garcia (Sociedade Pernambucana de Ortodontia), Rubens S. de Lima (Sociedade Paulista de Ortodontia), Jairo Curado de Freitas (Sociedade Goiana de Ortodontia) e João Grimberg (Sociedade Paulista de Ortodontia). comissão de reestruturação presidida por Manoel Carlos Müller de Araújo. No dia 15 do mesmo mês, em nova Assembléia Geral Extraordinária, elegeu-se a seguinte diretoria (1963/1964): Pau1o Affonso de Freitas (presidente), Manoel Carlos Müller de Araújo (vice-presidente), Homero Morelli (primeiro tesoureiro) e Oswaldo Farina (segundo tesoureiro). $\mathrm{O}$ estatuto da nova entidade foi aprovado no dia 18 de fevereiro de 1963. A SPO patrocinou a realização de vários Congressos Paulistas de Ortodontia, com a presença de ortodontistas de renome mundial, tendo o primeiro deles ocorrido em 1968 (Fig. 18) ${ }^{31}$. Em 1978 foi inaugurada sua sede própria. A SPO possui ainda uma Escola de Aperfeiçoamento Profissional, onde são desenvolvidos diversos trabalhos, entre os quais cursos de especialização em Ortodontia e Ortopedia Funcional dos Maxilares ${ }^{15}$.

\section{Associação Brasileira de Ortodontia}

Entre o final dos anos 60 e início dos anos 70 foram fundadas a Sociedade Ortodôntica de Begg do Estado da Guanabara (1969), a Sociedade Paranaense de Ortodontia (1972) e a Sociedade Gaúcha de Ortodontia (1975). Na década seguinte, surgiram a Sociedade Mineira de Ortodontia e a Sociedade Capixaba de Ortodontia, ambas em $1985^{47}$. Com o crescente incremento do número de entidades estaduais, tornou-se necessária a existência de uma associação especializada, ao nível nacional, que representasse a todos ${ }^{48}$.

Em 25 de janeiro de 1994, na sede da Sociedade Paulista de Ortodontia, na Rua do Livramento, 243, na cidade de São Paulo, foi fundado o Colégio Brasileiro de Ortodontia que, posteriormente, passou à denominação de Associação Brasileira de Ortodontia (ABOR) (Fig. 19). Estiveram presentes representantes das entidades ortodônticas dos estados de São Paulo, Rio Grande do Sul, Goiás, Minas Gerais, Paraná e Pernambuco. Na oportunidade, foi eleita a diretoria provisória composta dos seguintes profissionais: Eros Petrelli (presidente), Jairo Corrêa (vice-presidente) e Gerson I. Köhler 
(secretário). A associação recém criada tinha a finalidade de agrupar todas as entidades estaduais de Ortodontia e o Grupo de Professores de Ortodontia e Odontopediatra. Posteriormente, após a aprovação de seu estatuto, foi eleita uma nova diretoria, sendo ratificados os membros da diretoria provisória ${ }^{21}$.

No presente, a ABOR é constituída por uma diretoria com competência executiva e um conselho superior, composto por 21 sociedades estaduais, do Distrito Federal e mais o representante do Grupo de Professores de Ortodontia e Odontopediatra. Em maio de 1995 passou a representar a Ortodontia brasileira no cenário internacional, tornando-se filiada da World Federation of Orthodontists. Realiza a cada dois anos um congresso internacional com a participação de todas as sociedades estaduais ${ }^{21}$. Em setembro de 2002 foi registrada em cartório a ata de fundação do Board Brasileiro de Ortodontia e Ortopedia Facial (BBO), cujo estatuto foi aprovado pelo Conselho Superior da ABOR em 2001. O BBO tem como finalidade estimular a obtenção de padrões de excelência clínica no exercício da Ortodontia no Brasil, avaliando os conhecimentos básicos e a habilidade clínica do ortodontista e propiciando à comunidade um modo de avaliação dos serviços e cuidados a ela prestados ${ }^{25}$.

\section{CONSIDERAÇÕES FINAIS}

Escrever sobre o desenvolvimento da Ortodontia no Brasil não é uma tarefa simples. É necessário buscar fontes que remontam ao final do século XIX, num país sem tradição de preservar sua memória. Para serem atingidas as propostas deste trabalho foram consultados livros, capítulos de livros, artigos científicos e páginas da internet, o que permitiu desenvolver as seguintes linhas de discussão:

1) A Ortodontia, enquanto disciplina do curso de Odontologia, só passaria a existir oficialmente no Brasil a partir de 1925.

Conforme foi visto anteriormente, o Decreto
1.764 de 14 de maio de 1856 exigia dos candidatos a dentista o conhecimento dos meios de confecção das peças da Ortopedia Dentária ${ }^{10}$. Porém, quando o governo imperial instituiu oficialmente, através do Decreto 9.311 , de 25 de outubro de 1884, o curso de Odontologia nas Faculdades de Medicina do Rio de Janeiro e Bahia, a matéria Ortopedia Dentária não constava da lista de disciplinas que constituíam o curso. Constava, porém, a Prótese Dentária ${ }^{10}$.

A explicação para esse fato pode ser encontrada no capítulo XIII do "Manual Odontológico" de autoria do professor Coelho e Souza (Da Orthodontosia): "....as correções se fazem por meio de aparelhos, que a Prótese ensina a confeccionar, segundo o caso da anomalia" ${ }^{42}$. No prefácio do livro "Prótese Dentária", o professor Coelho e Souza esclarece melhor a questão44: "Com o desenvolvimento que assumiu a Odontologia nestes últimos tempos, a Prótese está sujeita a desdobrarse em varias especialidades, a saber: 1) Coroas e Pontes; 2) Dentaduras; 3) Ortodontia e 4) Prótese Cirúrgica. A Ortodontia, ramo da Odontologia de grande importância, ocupa-se dos aparelhos de correção das anomalias dentárias, chamados aparelhos ortodônticos. Esta especialidade nos Estados Unidos atingiu tal grau de perfeição, que se chega a duvidar da possibilidade de se conseguir tudo que os especialistas prometem executar. Não é a Ortodontia que aqui praticam muitos dos nossos policlínicos, com extrações e aparelhos irracionais, mas a Ortodontia científica, que não retira um só elemento, por mais subversivo que pareça, à regularidade anatômica dos arcos dentários. Quando estivemos nos Estados Unidos, reconhecemos na Ortodontia, como lá a executam, tamanha responsabilidade profissional, que a excluímos do nosso programa de observação, por carência de tempo".

Percebe-se, então, a pouca atenção emprestada à Ortodontia, no Brasil, à época de Coelho e Souza. Ensinava-se a confecção de aparelhos ortodônticos da mesma forma que se fazia com as peças protéticas, na disciplina de Prótese Dentária, sem 
maiores preocupações com diagnóstico, planificação ou filosofia de tratamento. Foi justamente contra esse status quo que Angle havia se insurgido nos Estados Unidos. Demonstrando conhecimento da Odontologia como um todo, Coelho e Souza acompanhou a evolução natural do ensino odontológico ao separar a Ortodontia das demais subespecialidades da Prótese Dentária, estudadas no livro-texto de sua autoria.

Data apenas de 1925 a primeira referência oficial sobre o ensino da Ortodontia em nosso país. $\mathrm{O}$ Decreto 16.782, de 13 de janeiro de 1925, criava a Faculdade de Odontologia. Por esse Decreto, o curso seria de 3 anos, havendo, inclusive, a criação da cadeira de Ortodontia e Prótese dos Maxilares. A existência de tal cadeira, a partir de 1925, possibilitou que os assuntos referentes à Ortodontia começassem a merecer maior importância dentro do curso de Odontologia. O desmembramento definitivo das disciplinas de Ortodontia e Prótese ocorreu em 1931, através do Decreto ${ }^{\circ}{ }^{0} 19.852$, que, publicado no dia 11 de abril, criou a cadeira de Ortodontia e Odontopediatria ${ }^{10}$.

Mais de 30 anos depois, com o advento da organização departamental, introduzida na estrutura universitária a partir da Lei de Diretrizes e Bases (Lei $\mathrm{n}^{\circ}$ 4.024, de 20 de dezembro de 1961), ficou extinta a cátedra ou cadeira (Lei ${ }^{\circ} 5.539$, de 27 de novembro de 1968), acarretando a separação dessas duas disciplinas ${ }^{47}$, o que trouxe benefícios para ambas, pois proporcionou o início da reformulação de seu ensino.

É provável que o termo Ortopedia Dentária, utilizado pelo legislador em 1856, se referisse à construção de aparelhos ortodônticos rudimentares, possivelmente de origem européia. De acordo com o professor Salles Cunha ${ }^{17}$, no início do século XIX a Odontologia brasileira sofreu forte influência dos dentistas europeus que vieram clinicar em nosso país, oriundos, principalmente, da França. Porém, a partir da segunda metade deste século, passou a ocorrer a predominância da escola norte-americana, devido à condição de excelência alcançada pela Odontologia daquele país. De fato, o professor Coelho e Souza ${ }^{44}$ informa que a especialidade poderia ser denominada Orthodontosia, Orthopedia Dentaria (dois vocábulos de origem francesa) ou Orthodontia (origem inglesa).

Somente após o sucesso da Escola Angle, criada em 1900, é que a Ortodontia passaria a ser mais divulgada e respeitada no meio odontológico, justificando seu aparecimento, como disciplina, nas faculdades brasileiras. Esses fatos ajudam a explicar a ausência aparente da Ortodontia, por 41 anos (1884-1925), no currículo oficial dos cursos de Odontologia.

2) Não foram identificados, no Brasil, indícios da prática da Ortodontia em época anterior ao início do século XX.

Não obstante, alguns procedimentos ortodônticos já deveriam ser conhecidos dos dentistas brasileiros, ao menos teoricamente, desde a segunda metade do século XIX. De acordo com o Decreto 1.764 , de 14 de maio de 1856 , que regulamentou o exame a que os candidatos a dentista deveriam se submeter, perante a Faculdade de Medicina, para que pudessem se habilitar ao exercício da profissão, seria exigido o conhecimento dos "...meios de confeccionar as peças da Prótese e Ortopedia Dentária" (Cap. VII, Art. 81) ${ }^{10}$. Entretanto, não foi possível localizar qualquer dentista, ou mesmo qualquer prático, que se utilizasse desses procedimentos.

Quando o curso de Odontologia foi criado, em 1884, inicialmente junto à Faculdade de Medicina do Rio de Janeiro ${ }^{10}$, os assuntos referentes à Ortodontia eram estudados na cadeira de Prótese Dentária ${ }^{44}$. Como o professor Antônio Gonçalves Pereira da Silva, responsável pela matéria, foi contratado em 1896, pode-se supor que a partir dos últimos anos do século XIX ele tenha ensinado aos alunos daquele curso a confecção de alguns tipos de aparelhos ortodônticos. É difícil saber, entretanto, se o próprio Pereira da Silva praticou qualquer procedimento ortodôntico em sua clínica, pois nada consta em sua biografia ${ }^{17}$. 
Em algum momento da segunda década do século XX, Carlos de Almeida Lustosa iniciou suas primeiras tentativas (frustradas) de tratamento ortodôntico, as quais levaram-no a se especializar na Angle School of Orthodontia (1923). Portanto, em meados da terceira década do século 20 havia um especialista clinicando no Rio de Janeiro, ao lado de dentistas policlínicos que, de certa forma, também praticavam algum tipo de Ortodontia. Em São Paulo, Alberto F. Gomes confeccionava aparelhos protéticos e ortodônticos em 1928. Para esses profissionais, obter informações sobre Ortodontia não era tarefa fácil. Em língua portuguesa existia apenas um capítulo de livro, publicado pelo professor Augusto Coelho e Souza.

No final dos anos 30 começaram a se formar pequenos grupos de praticantes da Ortodontia, a exemplo do que aconteceu com os seguidores de Carlos Lustosa. Em 1939, o professor Carlos Alves da Costa publicou um livro inteiro dedicado à especialidade, facilitando muito o aprendizado daqueles que não dominavam outro idioma. Um grande problema era conseguir material ortodôntico: a única maneira era importar, um processo muito demorado e dispendioso.

Durante a década de 1940 alguns profissionais brasileiros foram se aperfeiçoar no exterior, notadamente nos Estados Unidos, iniciando um ciclo que se intensificaria na década seguinte. A partir dos anos 50, com o retorno de vários pós-graduados, a Ortodontia brasileira ingressaria numa nova fase, com o advento dos cursos de especialização, a fundação das primeiras entidades de classe e a possibilidade de aquisição de material através de uma firma especializada. Esses acontecimentos se desenrolaram nos estados do Rio de Janeiro e São Paulo, mas aos poucos seus efeitos passariam a ser sentidos em outras regiões do país. Essa década pode ser considerada um divisor de águas da Ortodontia nacional, caracterizada pelo começo de uma crescente efervescência cultural, cujo símbolo maior talvez seja a realização da I Semana Paulista de Ortodontia, primeiro evento do gênero a reunir ortodontistas de vários estados da federação. De acordo com o professor Manoel Carlos Müller de Araújo7: "A partir da década de 1950, iniciava-se uma nova fase de desenvolvimento da Ortodontia no Brasil. Muitos foram os que passaram a buscar conhecimentos ortodônticos fora do país, trazendo informações técnicas, conceitos básicos e toda uma gama de novos termos e definições, quase sempre em língua inglesa".

Nos anos 60 ocorreu a consolidação do curso de pós-graduação do Rio de Janeiro e a abertura dos cursos de Piracicaba e São Paulo, aos quais viria se juntar o de Bauru, em 1973. Na década de 1970 estabelece-se um mercado razoável para os produtos ortodônticos, determinando o aparecimento de pequenos fabricantes e, finalmente, a construção da fábrica da Brasil Orthodontic. A literatura nacional avança mais um passo com a publicação do livro-texto organizado pelo professor Sebastião Interlandi. No Paraná (1972) e no Rio Grande do Sul (1975) surgem novas entidades de classe, congregando os ortodontistas daqueles estados. O ensino alcança o nível do strictu sensu, com o início dos cursos de mestrado no Rio de Janeiro, São Paulo e Piracicaba. Em 1976 aparece o primeiro curso de pós-graduação fora do eixo Rio-São Paulo, criado na Faculdade de Odontologia da UFRGS.

Nos anos 80 ocorreu um aumento expressivo no número de cursos de especialização, o que seria uma constante nas décadas vindouras. A Brasil Orthodontic encerra suas atividades. Porém, com o mercado em expansão, surgem vários outros fabricantes de material ortodôntico. O mesmo acontece no campo da literatura, com a publicação de mais de uma dezena de novos títulos. Cursos de doutorado iniciam suas atividades, permitindo a obtenção do título no próprio país e criando de vez as bases para o surgimento de uma nova consciência científica na Ortodontia brasileira.

Com o aumento do número de entidades de classe estaduais, em 1994 foi fundado o Colégio Brasileiro de Ortodontia, posteriormente modi- 
ficado para Associação Brasileira de Ortodontia (ABOR), com o objetivo de congregá-las em nível nacional. No início do século XXI o preocupante aumento no número de cursos de especialização gerou a necessidade de avaliar os conhecimentos dos novos especialistas. O Board Brasileiro de Ortodontia e Ortopedia Facial (BBO) foi criado em 2002 para desempenhar esta função.

Analisando todos os acontecimentos, fica evidente que a Ortodontia brasileira evoluiu muito em todos estes anos. Mas apesar de extremamente importante o que já foi feito e conseguido, mais importante ainda é o que pode ser feito para seu aperfeiçoamento futuro. O que parecia ser uma solução até há pouco tempo acabou se transformando num dos grandes problemas atuais: o crescente número de cursos de pós-graduação, muitos dos quais de qualidade duvidosa. Atualmente (2007) estão em atividade 315 cursos de especialização em Ortodontia ${ }^{18}$. Assunção ${ }^{8}$ observou um aumento de 553,65\%, em 12 anos (1993-2005). E ainda mais impressionante: no intervalo de apenas um ano (2006-2007), ocorreu um acréscimo de $38,76 \%$. Também preocupado com esta situação, Petrelli ${ }^{36}$ ressaltou a importância da criação de normas específicas para a abertura e para a revalidação destes cursos, contemplando itens como estrutura física adequada e corpo docente qualificado, visando a melhor formação do especialista em Ortodontia.

Muitas vezes é preciso conhecer o passado para entender o presente. A Ortodontia brasileira passou por um longo processo de evolução. Desde que nossos ortodontistas pioneiros trouxeram para o Brasil a nova ciência, até a criação dos cursos de doutorado em nosso país, um longo caminho foi percorrido. Durante um período de aproximadamente 50 anos, o esforço das instituições de ensino, aliado ao das entidades de classe, contribuiu para sedimentar seu desenvolvimento científico. No presente momento, parece sensato supor que o próximo passo deverá ser o estabelecimento de normas que regulamentem a pós-graduação, de modo a aprimorar a formação profissional dos novos especialistas.

\title{
Development of Orthodontics in Brazil and in the world
}

\begin{abstract}
Education, organization and literature. Every scientific specialization rests upon these three foundations. Concerning to orthodontics it could not be different. The way how orthodontics was implanted into the Brazilian official education, organized around its class associations and what kind of specialized literature was available to its precursors was related in the present paper. Precursors like Antônio Gonçalves Pereira da Silva, probably the first one to teach techniques to make orthodontic appliances. Carlos de Almeida Lustosa, the first Brazilian who become a specialist. Carlos Alves da Costa, the author of the first text-book written in Portuguese entirely dedicated to orthodontics. On the other hand, to understand the way how these changes took place and correlate them to the overall Orthodontics evolution, an historical summary of its global universe was organized. In accordance to the present findings, it can be stated that it was necessary 50 years, approximately, to occur the post-graduation centers consolidation in Brazil. It is also true that the effort of the education institutions and class associations contributed to create the foundations of the Brazilian orthodontics scientific development. At the present moment, however, it seems to be of common-sense to suppose that the next step should be the establishment of rules that can regulate the post-graduation programs, in order to improve the new specialists professional formation.
\end{abstract}

Key words: Brazilian Orthodontics - history. Brazilian Orthodontics - education. Brazilian Orthodontics - precursors. Brazilian Orthodontics - literature. Brazilian orthodontics - class associations. 


\section{REFERÊNCIAS}

1. ANGLE, E. H. Evolution of Orthodontia: recent developments. Dental Cosmos, Philadelphia, v. 54, no. 8, p. 853-867, 1912.

2. ANGLE, E. H. Some new forms of orthodontic mechanism, and the reasons for their introduction. Dental Cosmos, Philadelphia, v. 58, no. 9, p. 969-994, 1916

3. ANGLE, E. H. The latest and best in orthodontic mechanism. Dental Cosmos, Philadelphia, v. 70, no. 12, p. 1143-1158, 1928.

4. ANGLE, E. H. Evolution of Orthodontia: recent developments. Dental Cosmos, Philadelphia, v. 71, no. 2, p. 164-174, 1929.

5. ANGLE, E. H. Evolution of Orthodontia: recent developments. Dental Cosmos, Philadelphia, v. 71, no. 3, p. 260-270, 1929.

6. ANGLE, E. H. Evolution of Orthodontia: recent developments. Dental Cosmos, Philadelphia, v. 71, no. 4, p. 409-421, 1929.

7. ARAÚJO, M. C. M. Prefácio. In: INTERLANDI, S. Ortodontia, mecânica do arco de canto: introdução à técnica. São Paulo: Sarvier, 1986.

8. ASSUNÇÃO, P. S. Para onde vamos? Rev. SBO, São Paulo, v. 5, n. 3, p. 174-175, jan./mar. 2006

9. BARACCHINI, R. Ortodontia: o início. Ortodontia. Programa Oficial do IV Encontro Nacional de Ortodontistas da SPO. São Paulo, 1993.

10. BRITTO, A. A. A Odontologia através da Legislação Federal. Rio de Janeiro: Imprensa Federal, 1940.

11. BROADBENT, H. B. The face of the normal child. Angle Orthod., Appleton, v. 7, no. 4, p. 183-208, 1937

12. BRODIE, A. G.; DOWNS, W. B.: GOLDSTEIN, A.; MYER, E. Cephalometric appraisal of orthodontic results. Angle Orthod., Appleton, v. 8, no. 4, p. 261-265, 1938.

13. CAPONI, G. A técnica Tip-Edge. Ortodontia. Programa Oficial do IV Encontro Nacional de Ortodontistas da SPO. São Paulo, 1993.

14. COMISSÃO ORGANIZADORA. Livro do $7^{\circ}$ Encontro dos ExAlunos de Ortodontia da UFRJ (Editorial). Rio de Janeiro, 1992.

15. CORREA, O. SPO: uma realidade. Ortodontia. Programa Oficial do IV Encontro Nacional de Ortodontistas da SPO. São Paulo, 1993.

16. COSTA, C. A. Ortodontia. Niterói: Gráfica Dias Vasconcelos, 1939

17. CUNHA, E. S. História da Odontologia no Brasil (1500-1900). 3. ed. Rio de Janeiro: Ed. Científica, 1963.

18. CURSOS de Especialização. Disponível em: <http://www.cfo. org.br/index.htm>. Acesso em: 15 jan. 2007.

19. DAMICO, F. Editorial. Livro do VI Encontro de Pós-Graduados em Ortodontia da UFRJ. Maceió, 1990.

20. FREITAS, P. A. História da Ortodontia no Brasil. Ortodontia. Programa Oficial do IV Encontro Nacional de Ortodontistas da SPO. São Paulo, 1993.

21. FUNDAÇÃO da ABOR. Disponível em: <http://www.abor.org. br/historia.htm>. Acesso em: 26 dez. 2006.

22. GUANABARA. Disponível em: <http://pt.wikipedia.org/wiki/ Guanabara>. Acesso em: 26 dez. 2006

23. HAHN, G. W. Edward Hartley Angle (1855 - 1930). Am. J. Orthod., St. Louis, v. 51, no. 6, p. 529-535, 1965.

24. HARRADINE, N. W. T. Self-ligating brackets: where are we now? J. Orthod., London, v. 30, no. 3, p. 262-273, Sept. 2003

25. HISTÓRICO BBO. Disponível em: <http://www.bbo.org.br>. Acesso em: 30 dez. 2006.

26. INDICADOR profissional. A Odontologia moderna. São Paulo, v. 2, n. 9, p. 32, 1928 .

27. INTERLANDI, S. Ortodontia: bases para a iniciação. São Paulo: Ed. da USP, 1977.

28. JACOBSON, B. N. História da Ortodontia nos Estados Unidos da América. In: INTERLANDI, S. Ortodontia: bases para a iniciação. São Paulo: Ed. da USP, 1977.

29. LUSTOSA, C. A. A Orthodontia e a creança. Rio de Janeiro: Typographia Leuzinger, 1924.

30. LUSTOSA, C. A. Algumas causas das malocclusões dentarias. Rio de Janeiro: Typographia Leuzinger, 1932.
31. MACHADO, C. R. História da Ortodontia no Brasil. In: PETRELLI, E. (Coord.). Ortodontia contemporânea. São Paulo: Sarvier, 1988

32. MARTINS, J. E. S. Memorial. Rio de Janeiro: Faculdade de Odontologia da UFRJ, 1982

33. MOURA, C. R. Teoria e técnica de Begg. São Paulo: Panamed, 1983.

34. OLIVEIRA, A. M. B. T. L. A formação da Odontologia no Brasil.Rio de Janeiro: Faculdade de Odontologia da UFRJ, 1981.

35. PATRONO Disponível em: <http://www.sogaor.org.br/patrono/ index.asp>. Acesso em: 15 maio 2007

36. PETRELLI, E. A terceirização da Ortodontia. J. Brás. Ortodon. Ortop. Facial, Curitiba, v. 12, n. 62, p. 116, mar./abr. 2005.

37. RIEDEL, R. A. Edward H. Angle: the growth and development of a man, an organization, and a specialty. Angle Orthod., Appleton, v. 57, no. 2, p. 91-97, 1987.

38. RING, M. E. Dentistry: an illustrated history. 3rd ed. New York: Abradale Press, 1993.

39. ROTHIER, E. K. Sociedade Brasileira de Ortodontia: sua história e trajetória científica. Rio de Janeiro: SBO, 2005.

40. SHANKLAND, W. M. The American Association of Orthodontists: the biography of a speciality organization. St. Louis: The AAO, 1971.

41. SOUZA, A. C.; CARVALHO, A. D. Manual odontologico. 3. ed. Juiz de Fora: Typographia d'O Pharol, 1910.

42. SOUZA, A. C.; CARVALHO, A. D. Manual odontologico. 4. ed. Lisboa: Typographia do Annuario Commercial, 1912.

43. SOUZA, A. C.; CARVALHO, A. D. Manual odontologico. 5. ed. Rio de Janeiro: Pap. e Typ., 1917.

44. SOUZA, A. C.; CARVALHO, A. D. Manual odontológico: prothese dentaria - corôas e pontes. 8. ed. Juiz de Fora: Companhia Dias Cardoso, 1938

45. TWEED, C. H. Clinical Orthodontics. St. Louis: C. V. Mosby, 1966.

46. VADEN, J. L.; DALE, J. G.; KLONTZ, H. A. The Tweed-Merrifield edgewise appliance: philosophy, diagnosis and treatment. In: GRABER, T. M.; VANARSDALL, R. L. Orthodontics: currents principles and techniques. 2nd ed. St. Louis: Mosby Year Book, 1994

47. VILELLA, O. V. A história da Ortodontia no Brasil. 1. ed. Rio de Janeiro: Ed. Pedro Primeiro, 1995.

48. VILELLA, O. V. Ortodontia e ortopedia facial. In: ROSENTHAL, E. A Odontologia no Brasil no século XX. São Paulo: Ed. Santos, 2001

49. WAHL, N. Orthodontics in 3 millennia. Chapter 1: antiquity to the mid-19th century. Am. J. Orthod. Dentofacial Orthop. Saint Louis, v. 127, no. 2, p. 255-259, 2005.

50. WAHL, N. Orthodontics in 3 millennia. Chapter 2: entering the modern era. Am. J. Orthod. Dentofacial Orthop., St. Louis, v. 127 , no. 4 , p. 510-515, 2005.

51. WAHL, N. Orthodontics in 3 millennia. Chapter 3: the profissionalization of Orthodontics. Am. J. Orthod. Dentofacial Orthop., St. Louis, v. 127, no. 6, p. 749-753, 2005.

52. WAHL, N. Orthodontics in 3 millennia. Chapter 7: facial analysis before the advent of the cephalometer. Am. J. Orthod. Dentofacial Orthop., St. Louis, v. 129, no. 2, p. 293-298, 2006.

53. WEINBERGER, B. S. Orthodontics: an historical review of its origin and evolution. St. Louis: C. V. Mosby, 1926.

54. WUERPEL, E. H. The lengthening shadow of a man. Angle Orthod., Appleton, v. 17, no. 1, p. 3-9, 1947.

55. ZACHRISSON, B. U. Bonding in Orthodontics. In: GRABER, T. M.; VANARSDALL, R. L. Orthodontics: currents principles and techniques. 2nd ed. St. Louis: Mosby Year Book, 1994.

\section{Endereço para correspondência}

Oswaldo de Vasconcellos Vilella

Rua São Paulo, $n^{\circ} 32$

CEP: 24.040-110 - Niterói / RJ

E-mail: ovilela@wnetrj.com.br 